Article

\title{
Hybrid Fluorescent Poly(silsesquioxanes) with Amide- and Triazole-Containing Side Groups for Light Harvesting and Cation Sensing
}

\author{
Maria Nowacka*(D), Tomasz Makowski (iD) and Anna Kowalewska ${ }^{(D)}$ \\ Centre of Molecular and Macromolecular Studies, Polish Academy of Sciences, Sienkiewicza 112, \\ 90-363 Łódź, Poland; tomekmak@cbmm.lodz.pl (T.M.); anko@cbmm.lodz.pl (A.K.) \\ * Correspondence: mnowacka@cbmm.lodz.pl; Tel.: +48-42-680-32-03
}

Received: 28 July 2020; Accepted: 6 October 2020; Published: 10 October 2020

check for updates

\begin{abstract}
Hybrid polymers containing pyrene (Py) units bound to linear poly(silsesquioxane) (LPSQ) chains through flexible linkers containing heteroatoms ( $, \mathrm{N}, \mathrm{O}$ ) (LPSQ-triazole-Py and LPSQ-amide-Py) exhibit intense fluorescence emission, both in very diluted solutions $\left(\mathrm{c}=10^{-8} \mathrm{~mol} / \mathrm{L}\right)$ and in the solid state. The materials are thermally stable and exhibit good thin film forming abilities. Their optical and physicochemical properties were found to be strongly dependent on the structure of the side chains. Comparative studies with octahedral silsesquioxane (POSS) analogues (POSS-triazole-Py and POSS-amide-Py) emphasized the role of the specific double-strand architecture of the LPSQ backbone and distribution of side Py groups for their photo-luminescent properties. The new hybrid materials were tested as fluorescence energy donors to red-emitting dyes (Nile Red and Coumarine 6). All the silsesquioxanes studied were found to be able to transfer FL emission energy to Coumarin 6, irrespectively of their spatial structure. However, due to the differences in the wavelength range of FL emission, only LPSQ-triazole-Py were able to act as energy donors to Nile Red. The Py-grafted LPSQ may be also applied for development of soluble and highly emissive chemosensors. Their fluorescent nature was explored for the detection of $\mathrm{Cu}(\mathrm{II}), \mathrm{Fe}(\mathrm{III}), \mathrm{Co}(\mathrm{II}), \mathrm{Ag}(\mathrm{I})$, $\mathrm{Hg}(\mathrm{II}), \mathrm{Mg}(\mathrm{II}), \mathrm{Ca}(\mathrm{II}), \mathrm{Pb}(\mathrm{II})$ and $\mathrm{Zn}$ (II). The morphology of the side chains and hydrogen-bonding interactions influenced the sensing capacity of all the studied materials.
\end{abstract}

Keywords: poly(silsesquioxanes); fluorescence; optical activity; pyrene; fluorescence energy transfer; cation sensing

\section{Introduction}

With fast growing awareness of environmental issues, an increasing level of pollution in the natural environment and the search for new reproducible energy sources, the demand for technologies has been shifted to novel intelligent materials. Organic light-emitting diodes [1], organic photovoltaics [2], field effect transistors [3] or biosensors are the focus of these studies and potential applications. Derivatives of pyrene (Py) are organic $\pi$-conjugated molecules that exhibit strong absorbance, high quantum yield and good photochemical stability [4,5]. Those optoelectronic properties may be of advantage in light harvesting systems based on nonradiative excited state energy transfer (EnT) from antenna chromophores to acceptor molecules in the ground state [6,7]. The EnT in artificial light-harvesting systems occurs through Förster resonance energy transfer (FRET) [8].

Green light emitting Py excimers are formed when geometrical overlap of aromatic rings is provided. Highly organized systems, such as crystals of Py-containing molecules emit almost exclusively excimer fluorescence in the solid state [9]. Yet, preparation of thin fluorescent films that would exhibit high Py excimer emission may be a problem. Luminescence decrease or quenching is 
quite often observed at high concentrations (in solution and in solid amorphous state) due to formation of nanoaggregates. Such self-quenching phenomena may challenge functions of OLED's or artificial light-harvesting antenna [10].

Fluorescence spectroscopy is also widely used for environmental and biological studies due to the low detection limit, selectivity, rapid response and applicability for bioimaging [11-13]. Py derivatives being highly effective fluorophores are frequently used as fluorescent probes (e.g., for detection of changes in temperature [14], pressure [15], $\mathrm{pH}$ [16], concentration of gases [17], organic molecules [18], inorganic anions [19] and metal cations [20]). The drawback of the use of low molecular weight pyrene derivatives is that efficient interactions between chromophores occur at high concentrations. Under such conditions, Py fluorescence is quite often quenched.

Therefore, of high interest are novel molecules or macromolecules that allow for efficient use of Py fluorophores in dilute solutions and suppress $\pi$-stacking-induced molecular aggregation of pyrene in solid state and concentrated solutions. One of the possible resolutions is preparation of Py labeled polymer materials. Various types of optically active polymers have been prepared to date-e.g., Py functionalized polyacetylenes [21], poly(N-vinyl-2-pyrrolidone) [22], copolymers prepared though radical polymerization of n-butyl methacrylate and Py coupled methacrylates [23], poly(1-pyrenylmethoxycarbonylmethylene) [24], poly(methoxy diethylene glycol methacrylate) [25] and polystyrene [26]. Additionally, Py containing silicon-based materials have been prepared recently. Octavinylsilsesquioxane functionalized with Py exhibited good optical properties in solution and solid state and was successfully tested for application in electroluminescent devices [27,28]. However, properties of polyhedral silsesquioxanes (poor film forming properties, crystal structure, low molecular weight) exclude them from some applications, such as production of large area displays. Grafting pyrene onto poly(siloxanes) [29] resulted in better properties and expanded the area of their possible applications. Due to the unique architecture and properties, even better results can be achieved with linear poly(silsesquioxanes), but not much research has been dedicated to their preparation to date. We have recently shown that optically active linear poly(2-(pyren-1-yl)vinyl)silsesquioxanes (LPSQ-Py) bearing Py moieties in their side chains are highly emissive, even in very dilute solutions [30]. They exhibited almost exclusively intramolecular excimer emission and scarce fluorescence quenching. The effect was ascribed to the fixed position of Py groups linked with rigid spacers to the double-strand silsesquioxane backbone.

It can be thus assumed that the flexibility and interactions between the side chains linking Py and LPSQ backbone may influence interactions between chromophores. In this study, we present a new type of linear polysilsesquioxanes, LPSQ-R-Py, bearing nucleophilic oxygen, nitrogen or sulphur atoms embedded in the spacers (-R-) between the polymer backbone and Py moieties. We thoroughly studied the influence of the side chains structure with regard to the optical properties of LPSQ (characteristic position of FL bands and intensity of emission) both in dilute solutions and in the solid state. In order to determine the role of characteristic architecture of LPSQ, we also studied properties of their octahedral core silsesquioxane analogues (polyhedral oligomeric silsesquioxanes, POSS).

The improved efficiency of interactions between side chromophores in LPSQ-R-Py allowed for efficient EnT to organic dyes [9-diethylamino-5-benzo[ $\alpha]$ phenoxazinone (Nile Red) and 2H-chromen-2-one (Coumarin 6)]. The effect of different paramagnetic [Cu(II), Fe(III), Co(II)] and diamagnetic $[\mathrm{Ag}(\mathrm{I}), \mathrm{Hg}(\mathrm{II}), \mathrm{Mg}(\mathrm{II}), \mathrm{Ca}(\mathrm{II}), \mathrm{Pb}(\mathrm{II}), \mathrm{Zn}(\mathrm{II})]$ metal cations on optical properties of the LPSQ-R-Py was also examined. Materials with triazole linkers in side groups exhibited high sensitivity toward $\mathrm{Cu}(\mathrm{II})$ and $\mathrm{Ag}(\mathrm{I})$ ions, and only slightly poorer sensitivity for $\mathrm{Hg}$ (II) and $\mathrm{Fe}(\mathrm{III})$. LPSQ-amide-Py detected Co(II), Fe(III) and Cu(II), yet the effect was not large. POSS-amide-Py was selective toward $\mathrm{Co}(\mathrm{II})$. 


\section{Materials and Methods}

\subsection{Materials}

Linear poly(vinylsilsesquioxanes) of regular structure and triethylsilyl end groups (LPSQ-Vi; $\mathrm{Mn}=1000 \mathrm{~g} / \mathrm{mol}$, PDI = 1.2) were prepared according to the published procedure [31]. 1,3,5,7,9,11,13,15Octavinylpentacyclo-[9.5.1.13,9.15,15.17,13]octasiloxane (POSS-Vi) was purchased from Hybrid Plastics (Hattiesburg, MS, USA) and used as received. Linear LPSQ-TG were prepared following a literature procedure [32]. POSS-TG was prepared in an analogous way. LPSQ-amide-Py and POSS-amide-Py were prepared through condensation of side -COOH groups of LPSQ-TG or POSS-TG with 1-aminopyrene. Silsesquioxanes bearing 3-chloropropyl side groups were prepared following the literature procedure (LPSQ-Cl [33] and POSS-Cl [34]). LPSQ- $\mathrm{N}_{3}$ and POSS- $\mathrm{N}_{3}$ were obtained via azidation of LPSQ-Cl and POSS-Cl, respectively. LPSQ-triazole-Py and POSS-triazole-Py were obtained via the copper(I)-catalyzed Huisgen cycloaddition of 1-ethynylpyrene to LPSQ- $\mathrm{N}_{3}$ or POSS- $\mathrm{N}_{3}$. (3-Azidopropyl)trimethoxysilane was prepared according to the modified literature procedure [35].

The detailed synthetic procedure and products characterization can be found in Supplementary Information.

Commercially available reagents (1-ethynylpyrene (96\%, ABCR, Karlsruhe, Germany), 1-aminopyrene (95\%, ABCR, Karlsruhe, Germany), $\mathrm{N}, \mathrm{N}, \mathrm{N}^{\prime}, \mathrm{N}^{\prime \prime}, \mathrm{N}^{\prime \prime}$-pentamethyldiethylenetriamine (PMDETA, 99\% Aldrich, Poznań, Poland), copper bromide (98\%, Alfa Aesar, Lancashire, UK), silica gel applied as a reagent and column chromatography solid phase (high purity grade, pore size 60A, 70-230 mesh; Aldrich, Poznań, Poland), potassium iodide (99\%, Aldrich, Poznań, Poland), sodium azide (99\% extra, Acros Organics, Geel, Belgium), thioglycolic acid (>99\%, Aldrich, Poznań, Poland), $\mathrm{MgSO}_{4}$ (pure, Chempur, Piekary Ślaskie, Poland)), 2,2-dimethoxy-2-phenylacetophenone (DMPA; 99\%, Acros Organics, Geel, Belgium)), p-phenylenediamine (pPDA, >99\%, Aldrich, Poznań, Poland), triethylamine ( $>98 \%$, Fluka, Gillingham, UK), $\mathrm{HCl}(36-38 \%$, Stanlab Sp. J., Lublin, Poland), 3-chloropropyltrichlorosilane (for synthesis; Aldrich, Poznań, Poland) and fluorescent dyes ((9-diethylamino-5-benzo[ $\alpha]$ phenoxazinone, Nile Red, extra pure; Roth, Worcester, UK) and 3-(2-Benzothiazolyl)-7-(diethylamino)coumarin (Coumarin 6; 98\%, Aldrich, Poznań, Poland)) were used as received.

Solvents used for the synthesis (tetrahydrofuran (THF) (Chempur, pure p.a.), dichloromethane (Chempur, pure p.a.), methanol (p.a., Chempur, Piekary Śląskie, Poland), toluene (p.a., Chempur, Piekary Ślaskie, Poland)) and N,N-dimethylformamide (DMF; p.a., Chempur, Piekary Ślaskie, Poland) were purified according to literature procedures [36]. Solvents used for spectroscopic studies (FL and absorption analysis): THF (spectroscopic grade; Alfa Aesar, Lancashire, UK) and $\mathrm{CHCl}_{3}$ (spectroscopic grade; Uvasol Merck, Darmstadt, Germany) were used as received.

\subsection{Instrumentation}

\subsubsection{Nuclear Magnetic Resonance (NMR)}

Liquid state ${ }^{1} \mathrm{H}$ NMR, ${ }^{13} \mathrm{C}$ NMR and ${ }^{29} \mathrm{Si} \mathrm{NMR}$ spectra were recorded in $\mathrm{CDCl}_{3}, \mathrm{CD}_{3} \mathrm{OD}$ or THF- $\mathrm{d}_{6}$ on a Bruker DRX-500 MHz spectrometer. Solid-state ${ }^{13} \mathrm{C}$ NMR and ${ }^{29} \mathrm{Si}$ NMR spectra were recorded on BRUKER Avance III 400 spectrometer (Bruker, Billerica, MA, USA) with high power decoupling (HP Dec) of direct polarization.

\subsubsection{Thermal Analysis}

Thermogravimetric analysis (TGA) of the prepared materials was performed in nitrogen atmosphere (heating rate $10^{\circ} \mathrm{C} / \mathrm{min}$, resolution 3, sensitivity 3) using a Hi-Res TGA 2950 Thermogravimetric Analyzer (TA Instruments, New Castle, DE, USA) with a platinum heating pan.

The samples were also studied using differential scanning calorimetry (DSC 2920 Modulated TA Instruments). Thermograms were taken for samples (sealed in aluminum pans) heated under 
nitrogen at the rate of $10^{\circ} \mathrm{C} / \mathrm{min}$ from room temperature to 200 (LPSQ/POSS-Cl), 180 (LPSQ/POSS-N N $_{3}$, 150 (LPSQ/POSS-triazole-Py) or $100^{\circ} \mathrm{C}$ (LPSQ/POSS-amide-Py, LPSQ/POSS-Vi). The samples were then cooled at $10^{\circ} \mathrm{C} / \mathrm{min}$ to $-50^{\circ} \mathrm{C}$ and heated again. The heating/cooling cycles were repeated trice.

\subsubsection{Fourier-Transform Infrared Spectroscopy (FTIR)}

Fourier transform infrared spectra were recorded with a Nicolet 380 FTIR spectrometer (Thermo Scientific, Waltham, MA, USA) for thin films of all products cast on crystal $\mathrm{KBr}$ windows. The technique of attenuated total reflectance (ATR) was applied for IR measurements, using a deuterated triglycine sulfate (DTGS) detector with a diamond ATR accessory Golden Gate (Nicolet 6700 spectrometer; Thermo Fisher Scientific, Waltham, MA, USA). The spectra were obtained by adding 64 scans at a resolution of $2 \mathrm{~cm}^{-1}$.

\subsubsection{Wide Angle X-Ray Scattering (WAXS)}

Wide-angle X-ray scattering (WAXS) measurements were performed using a $\mathrm{CuK} \alpha$ radiation source (Philips, Guildford, UK), operating at $30 \mathrm{kV}$ and $50 \mathrm{~mA}$. The diffraction patterns were recorded in the $2 \Theta$ scattering range from 1 to $37^{\circ}$. The typical time of acquisition was $7 \mathrm{sec}$. Samples were irradiated at the incident angle $(\alpha \mathrm{i})$ of $0.05^{\circ}$.

Measurements were carried out for thin layers prepared by the drop casting method from solutions in chloroform (LPSQ/POSS-triazole-Py) or DMF (LPSQ/POSS-amide-Py), $\mathrm{c}_{\mathrm{Py}}=10^{-3} \mathrm{~mol} / \mathrm{L}$.

\subsubsection{Atomic Force Microscopy (AFM)}

Morphology of thin films of LPSQ/POSS-triazole-Py and LPSQ/POSS-amide-Py was investigated with a Flex Axiom atomic force microscope with C3000 controller (Nanosurf AG, Liestal, Switzerland). The measurements were performed in air, using a noncontact mode. All of the images were prepared with a resolution of $512 \times 512$ data points.

Measurements were carried out for thin layers prepared by drop casting from solutions in chloroform (LSPQ/POSS-triazole-Py) and DMF (LPSQ/POSS-amide-Py), $\mathrm{c}_{\mathrm{Py}}=10^{-3} \mathrm{~mol} / \mathrm{L}$.

\subsubsection{Molecular Modelling}

Models of molecules of LPSQ/POSS-triazole-Py and LPSQ/POSS-amide-Py were constructed on the HyperChem platform [37]. The atomic point charges were calculated using the semi-empirical AM1 method and geometry was optimized by the molecular mechanics method (using MM+ force field parameter set with Polak-Ribiere energy minimization algorithms).

\subsubsection{Reflected Light Microscopy}

Thin films cast on silicon plates from solutions in DMF $\left(\mathrm{c}_{\mathrm{Py}}=10^{-3} \mathrm{~mol} / \mathrm{L}\right)$ were analyzed by reflected light microscopy with a Delta Optical light microscope (Delta Optical, Warszawa, Poland) equipped with a digital camera.

\subsubsection{Ultraviolet-Visible Spectroscopy (UV)}

UV-VIS measurements were performed using a Specord S600 spectrophotometer, associated with Win Aspect software version 2.3 (Analytik Jena AG, Jena, Germany).

Solutions of LPSQ/POSS-triazole-Py and LPSQ/POSS-amide-Py at different concentrations $\left(c_{\mathrm{Py}}=10^{-8}-10^{-3} \mathrm{~mol} / \mathrm{L}\right.$ ) were prepared in THF, $\mathrm{CHCl}_{3}$ and $\mathrm{DMF}$ and placed in $10 \mathrm{~mm}$ path length quartz cuvettes. Measurements in solid state were carried out for thin films spin coated on quartz plates from solutions of LPSQ/POSS-triazole-Py and LPSQ/POSS-amide-Py in chloroform $\left(\mathrm{c}_{\mathrm{Py}}=10^{-6} \mathrm{~mol} / \mathrm{L}\right)$. 


\subsubsection{Fluorescence Spectroscopy (FL)}

Fluorescence spectra were recorded at room temperature using selected excitation wavelengths with a Horiba Jobin Yvon, Fluorolog-3 spectrofluorometer (Horiba Jobin Yvon, Kioto, Japan). The slit size used for excitation and emission measurements was $2 \mathrm{~nm}$. Solutions of LPSQ/POSS-triazole-Py and LPSQ/POSS-amide-Py at different concentration $\left(\mathrm{c}_{\mathrm{Py}}=10^{-8}-10^{-3} \mathrm{~mol} / \mathrm{L}\right)$ were prepared in THF, $\mathrm{CHCl}_{3}$ and DMF and placed in quartz cuvettes of $10 \mathrm{~mm}$ path length. Solid state measurements were carried out for thin films spin coated on quartz plates from solutions in chloroform $\left(c_{\mathrm{Py}}=10^{-6} \mathrm{~mol} / \mathrm{L}\right)$.

\subsubsection{Fluorescence Energy Transfer}

Experiments with dye additives (Nile Red, Coumarin 6) were carried out for a chosen amount (1-200 $\mu \mathrm{L})$ of dye solution $\left(10^{-3} \mathrm{~mol} / \mathrm{L}\right.$, THF for triazole derivatives or DMF for amide derivatives) added to the solution ( $3 \mathrm{~mL}$ ) of LPSQ/POSS-triazole-Py in THF or LPSQ/POSS-amide-Py in DMF at concentration $10^{-6} \mathrm{~mol} / \mathrm{L}$ of Py groups.

\subsubsection{Detection of Metal Cations}

For measurements with metal cations (Zn (II), Ca (II), Pb (II), Hg (II), Cu (II), Co (II), Ag (I), Fe (III), Mg (II)), a chosen amount (1-200 $\mu \mathrm{L})$ of appropriate perchlorate (V) salt $\left(10^{-4} \mathrm{~mol} / \mathrm{L}\right.$, in THF for triazole derivatives or in DMF for amide derivatives) was added to the solution $(3 \mathrm{~mL})$ of LPSQ/POSS-triazole-Py in THF or LPSQ/POSS-amide-Py in DMF at concentration $10^{-6} \mathrm{~mol} / \mathrm{L}$ of Py groups.

\section{Results and Discussion}

\subsection{Synthesis, Structure and Thermal Properties of Fluorescent LPSQ}

LPSQ are linear counterparts of the well-known polyhedral oligomeric silsesquioxanes (POSS), but due to their polymeric nature and highly ordered double-chain structures, they exhibit completely different physicochemical properties (e.g., solubility, thermal stability) [32,38-40]. LPSQ with a highly regular backbone can be prepared by polycondensation of cyclotetrasiloxane-2,4,6,8-tetraols [31] or step-wise coupling polycondensation [33]. The latter method was used for the preparation of polymeric precursors-poly(3-chloropropylsilsesquioxanes) (LPSQ-Cl; $\mathrm{M}_{\mathrm{n}}=1400 \mathrm{~g} / \mathrm{mol}, \mathrm{M}_{\mathrm{w}}=1700 \mathrm{~g} / \mathrm{mol}$, PDI $=1.3$ - -used in this study. LPSQ-Cl were converted into poly(3-azidopropylsilsesquioxanes) (LPSQ-N ${ }_{3}$ ) that were subsequently grafted with 1-ethynylpyrene via copper(I)-catalyzed azide-alkyne cycloaddition (Scheme 1). Polyhedral oligomeric silsesquioxanes were modified in a similar way.

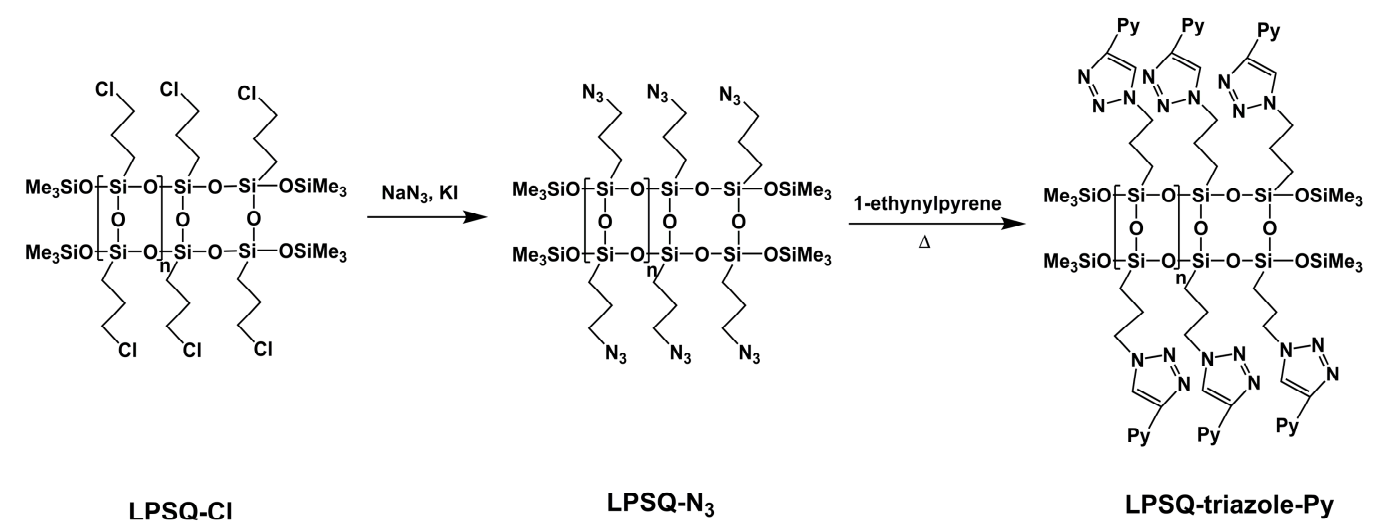

Scheme 1. Synthesis of LPSQ-triazole-Py via copper(I)-catalyzed azide-alkyne cycloaddition of 1-ethynylpyrene to LPSQ-N 3 (obtained from LPSQ-Cl precursor).

The reaction progress was monitored by FTIR spectroscopy. The assignment of IR characteristic bands is presented in Figure 1 and Table S3. The synthesis was carried out until the complete conversion 
of $-\mathrm{CH}_{2} \mathrm{CH}_{2} \mathrm{CH}_{2} \mathrm{Cl}$ groups into $-\mathrm{CH}_{2} \mathrm{CH}_{2} \mathrm{CH}_{2} \mathrm{~N}_{3}$ and then into $-\mathrm{CH}_{2} \mathrm{CH}_{2} \mathrm{CH}_{2}$-triazole. In the first step, disappearance of the band characteristic of stretching vibration of 3-chloropropyl groups $v(\mathrm{C}-\mathrm{Cl})$ $\left(\sim 700 \mathrm{~cm}^{-1}\right)$ was observed with simultaneous appearance of a new vibration typical for azide groups $v(\mathrm{~N}=\mathrm{N}=\mathrm{N})\left(\sim 2100 \mathrm{~cm}^{-1}\right)$.

During the conversion of octahedral POSS- $\mathrm{Cl}$ into POSS- $\mathrm{N}_{3}$, a reorganization of siloxane bonds was noted. A stable mixture of polyhedral oligomeric silsesquioxanes (octahedral POSS- $\mathrm{T}_{8}-\mathrm{N}_{3}$, decahedral POSS- $\mathrm{T}_{10}-\mathrm{N}_{3}$ and dodecahedral POSS- $\mathrm{T}_{12}-\mathrm{N}_{3}$ ) at 1:2:1 molar ratio was formed (Figure S3). The redistribution was reported before by Ervithayasuporn et al. [41]. The synthesis involves the use of a basic reagent (sodium azide, three-fold molar excess with respect to $-\mathrm{CH}_{2} \mathrm{CH}_{2} \mathrm{CH}_{2} \mathrm{Cl}$ groups) and is carried out in a solvent of high polarity (DMF). Under the applied reaction conditions, $\mathrm{NaN}_{3}$ plays a dual role of a source of azide groups and a nucleophile that induces cage rearrangement. It must be stressed that exactly the same composition of products was obtained if the reaction was carried out at $\left[\mathrm{NaN}_{3}\right]_{0} /[\mathrm{Cl}]_{0}=1 / 8$. The obtained mixture of polyhedral azides was used for the further studies. The organization of side substituents in linear ladder structure differs significantly from those of any of the obtained polyhedral silsesquioxanes, and thus, we did not separate the POSS components of the mixture. LPSQ-Cl suffered similar redistribution of siloxane bonds induced by $\mathrm{NaN}_{3}$. The SEC diagram (Figure S2) of the crude reaction product $\left(\mathrm{M}_{\mathrm{n}}=6100 \mathrm{~g} / \mathrm{mol}, \mathrm{M}_{\mathrm{w}}=18,500 \mathrm{~g} / \mathrm{mol}\right.$, PDI = 3.0) shows an increase in polydispersity with regard to LPSQ-Cl. Precipitation of the obtained material resulted in a product fraction $(Y=76 \%)$ of a narrow $M_{w} / M_{n}(P D I=1.3)$ and molecular weight $M_{n}$ of $1900 \mathrm{~g} / \mathrm{mol}$ (Table S2). The purified product was used for further studies. During the Hüisgen coupling step, the conversion of azide groups was confirmed by disappearance of the $v(\mathrm{~N}=\mathrm{N}=\mathrm{N})$ band in FTIR spectra. At the same time, vibration modes typical for a triazole ring- $v(\mathrm{~N}=\mathrm{N})\left(1434 \mathrm{~cm}^{-1}\right)$ and $v(\mathrm{C}=\mathrm{C})\left(1550 \mathrm{~cm}^{-1}\right)$ appeared. The structures of LPSQ-triazole-Py and POSS-triazole-Py were confirmed with ${ }^{1} \mathrm{H},{ }^{13} \mathrm{C}$ and ${ }^{29} \mathrm{Si} \mathrm{NMR}$ (in solution and solid state) (Supplementary Information).

LPSQ bearing vinyl groups (LPSQ-Vi; $\mathrm{M}_{\mathrm{n}}=1000 \mathrm{~g} / \mathrm{mol}$, PDI = 1.2) was used as the precursor for macromolecules with Py chromophores grafted through linkers containing amide groups (Scheme 2). It was converted into poly[2-(carboxymethylthio)-ethylsilsesquioxane] (LPSQ-TG) by photoinitiated addition of thioglycolic acid to the side vinyl groups, as we have previously described [32]. The addition occurred regioselectively with formation of the anti-Markovnikov product. LPSQ-amide-Py was obtained by condensation of the side - $\mathrm{COOH}$ groups of LPSQ-TG with 1-aminopyrene molecules. The solubility of linear oligomers with all side chains containing amide bond (LPSQ-amide100-Py) was low owing to strong interchain interactions (formation of hydrogen bonds connecting amide linkers, analogously to those observed in polyamides [42]) and attractive $\pi-\pi$ contacts between Py substituents. Due to the structural differences, the octa-substituted octahedral analogue (POSS-amide-Py) was very soluble in THF and DMF. To improve solubility of LPSQ bearing amide-Py groups and enable studies on their optical properties, soluble LPSQ-amide75-Py and LPSQ-amide50-Py, containing, respectively, 75 and $50 \%$ of Py substituted side chains, were prepared under the same synthetic protocol (Table S1).

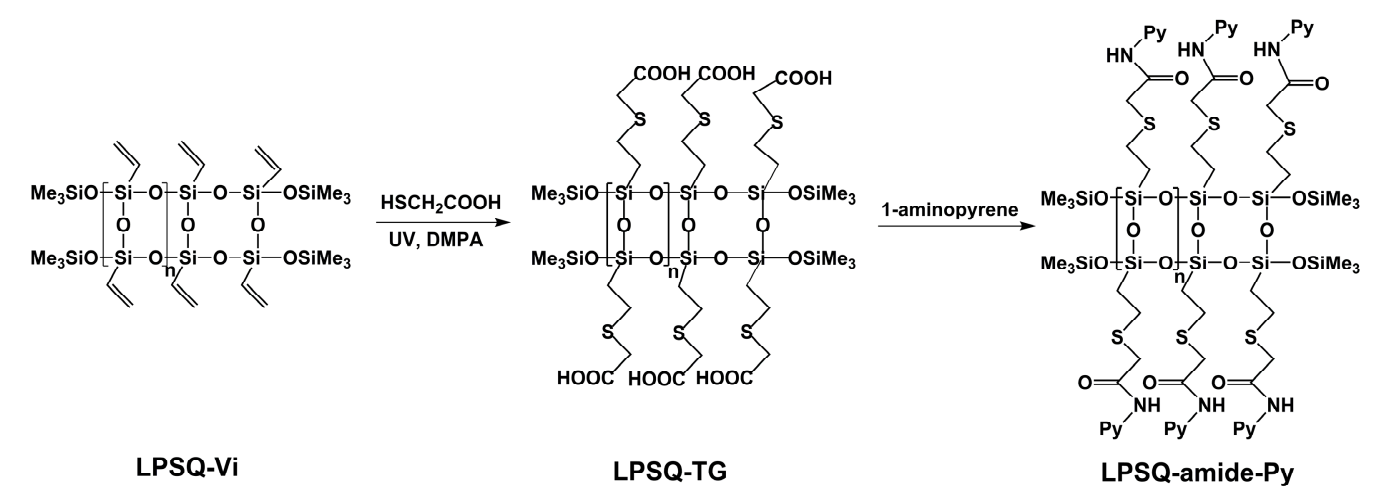

Scheme 2. Synthesis of LPSQ-amide-Py via condensation of carboxylic groups of LPSQ-TG and 1-aminopyrene. 
The reaction progress was monitored by FTIR and it was carried out until the planned conversion of carboxylic groups into amides occurred. The assignment of IR characteristic bands is presented in Figure 2 and Table S3. Amide bond formation was confirmed by disappearance of the vibration band typical for $v(\mathrm{C}=\mathrm{O})$ in carboxylic acids $\left(1750-1700 \mathrm{~cm}^{-1}\right)$ and formation of new bands characteristic of amides: $v(\mathrm{C}(\mathrm{O}) \mathrm{N})\left(1700-1600 \mathrm{~cm}^{-1}\right)$ and $v(\mathrm{C}-\mathrm{N})$ in combination with $\delta(\mathrm{N}-\mathrm{H})\left(1600-1500 \mathrm{~cm}^{-1}\right)$. The amount of amide groups in side chains influenced the position of vibrational bands. Increasing the ratio of amide groups led to the shift of $v(\mathrm{C}(\mathrm{O}) \mathrm{N})$ mode toward lower wavenumbers (from $1640 \mathrm{~cm}^{-1}$ for LPSQ-amide50-Py to $1618 \mathrm{~cm}^{-1}$ for LPSQ-amide100-Py). A similar position of the $v(\mathrm{C}(\mathrm{O}) \mathrm{N})$ band was found for POSS-amide-Py $\left(1624 \mathrm{~cm}^{-1}\right)$. All the obtained materials were characterized with ${ }^{1} \mathrm{H}$, ${ }^{13} \mathrm{C}$ and ${ }^{29} \mathrm{Si}$ NMR spectroscopy (in solution and in solid state) (Supplementary Information).

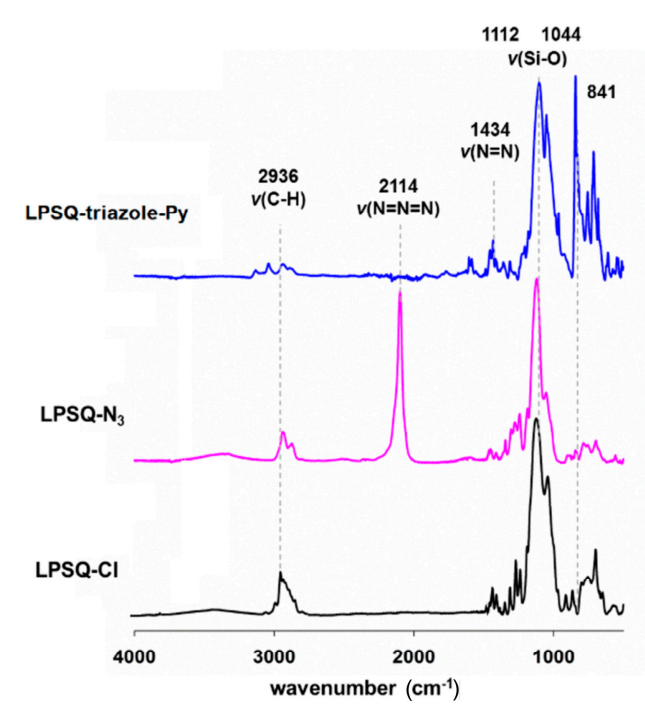

(a)

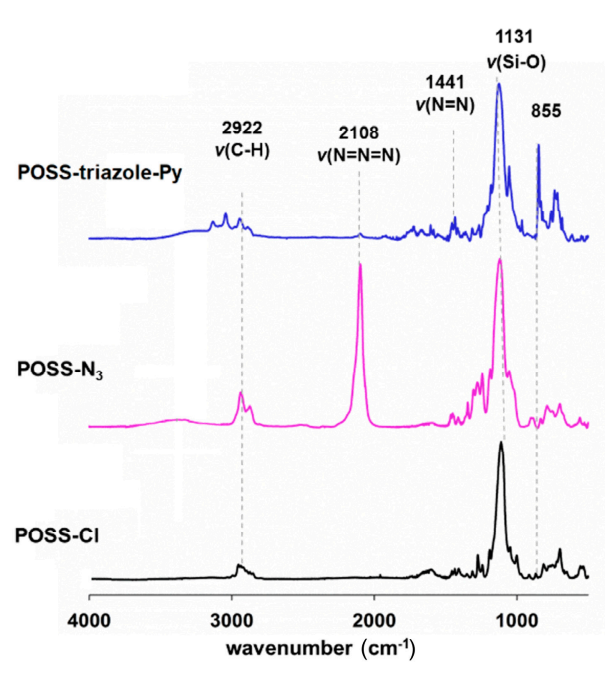

(b)

Figure 1. FTIR spectra plotted in absorbance mode (arbitrary units) of (a) LPSQ-triazole-Py and (b) POSS-triazole-Py along with spectra of the intermediate products.

Thermal characteristics of the obtained materials were assessed with TGA and DSC techniques (Figure 3, Figure 4 and Figure S4). Thermal stability of both triazole-containing silsesquioxanes increased in comparison to their azide precursors that underwent rapid sublimation at temperature $>235^{\circ} \mathrm{C}$. Azides are known to be thermosensitive and possible explosives. Their stability depends on their atom composition $\left(\left(\mathrm{N}_{\mathrm{C}}+\mathrm{N}_{\mathrm{O}}\right) / \mathrm{N}_{\mathrm{N}} \geq 3\right.$, where $\mathrm{N}$-number of atoms) [43]. Organic alkyl azides typically start to decompose at $180-200{ }^{\circ} \mathrm{C}$ [44]. Octakis(3-azidopropyl)octasilsesquioxanes were reported to be thermally stable up to $237^{\circ} \mathrm{C}$ [45], which is consistent with our results. We ascribed the observed similar thermal stability of POSS- $\mathrm{N}_{3}$ and LPSQ- $\mathrm{N}_{3}$ to the similar atom composition of these materials. LPSQ-triazole-Py and POSS-triazole-Py were thermally stable up to $\sim 350{ }^{\circ} \mathrm{C}$ in $\mathrm{N}_{2}$ atmosphere ( $5 \%$ weight loss temperature $\left(\mathrm{T}_{5 \%}\right)=353{ }^{\circ} \mathrm{C}$ and $352{ }^{\circ} \mathrm{C}$ for LPSQ and POSS, respectively) (Figure 3a and Figure S4a). A characteristic two step decomposition was observed for the triazole-silsesquioxanes and their 3-chloropropyl precursors. The two main decomposition stages of LPSQ-Cl leading to the high char yield $(60 \%)$ may be ascribed to the partial degradation of the organic moieties and then scission of $\mathrm{Si}-\mathrm{C}$ bonds at $\mathrm{T}>450{ }^{\circ} \mathrm{C}$, analogously to those reported for other POSS [46,47]. The first decomposition step of LPSQ-triazole-Py $\left(\mathrm{T}_{\mathrm{d} 1}=380^{\circ} \mathrm{C} ; 29 \% \mathrm{wt}\right.$ decrease $)$ occurred in the temperature range similar to $\mathrm{T}_{\mathrm{d} 1}$ of LPSQ-Cl. The char left after the second stage of weight loss $\left(\mathrm{T}_{\mathrm{d}}=443{ }^{\circ} \mathrm{C} ; 39 \%\right.$ wt decrease) is larger than that calculated for the inorganic residue formed by cleavage of $\mathrm{Si}-\mathrm{C}$ bonds. It suggests recombination of structural segments during the thermolysis and formation of a cross-linked material. This pathway may be supported by a larger 
amount of the char remaining at $600{ }^{\circ} \mathrm{C}$ after the decomposition of LPSQ-triazole-Py, while two-step $\mathrm{T}_{\mathrm{d} 5}$ were similar (Table 1 ).

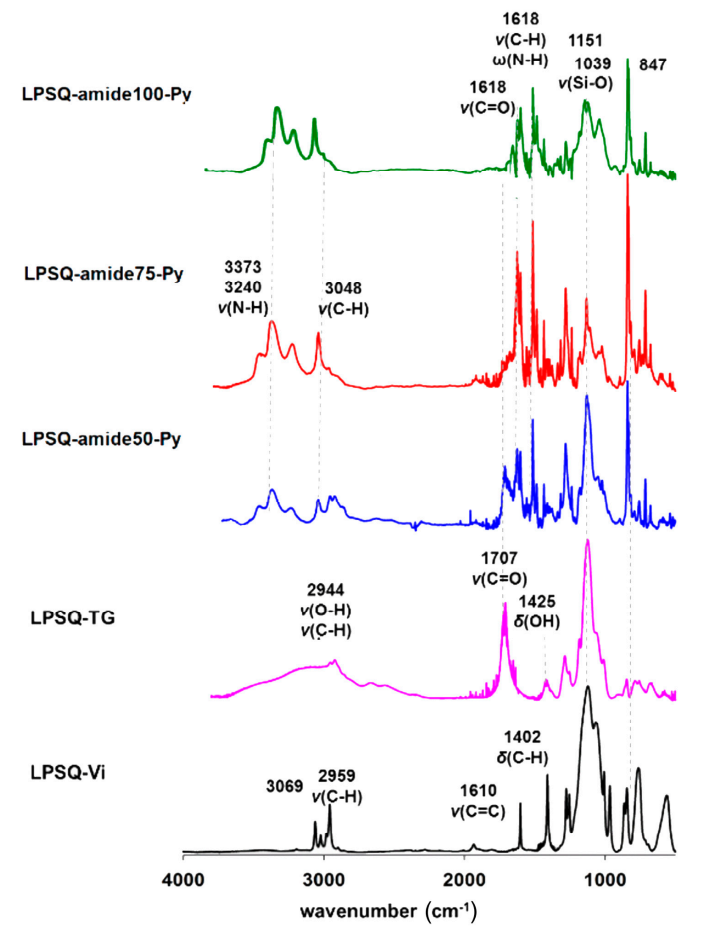

(a)

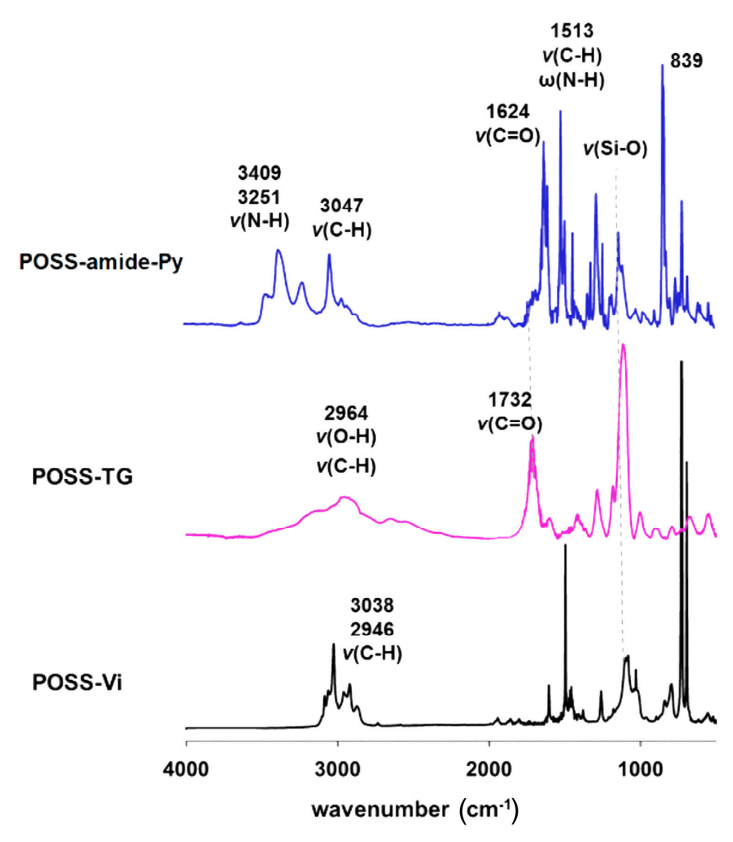

(b)

Figure 2. ATR-FTIR spectra plotted in absorbance mode (arbitrary units) of (a) LPSQ-amide-Py and (b) POSS-amide-Py along with spectra of the intermediate products.

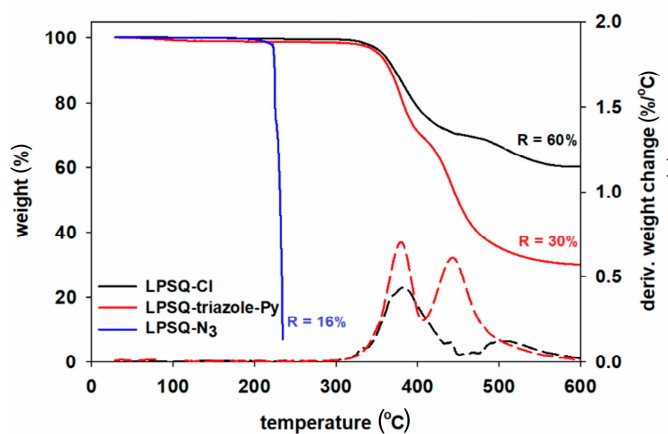

(a)

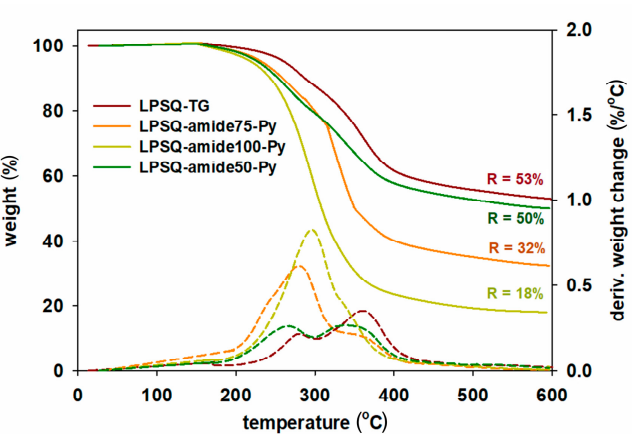

(b)

Figure 3. Thermogravimetric analysis of (a) LPSQ-triazole-Py and (b) LPSQ-amides-Py $\left(\mathrm{N}_{2}\right.$ atmosphere, $\left.10^{\circ} \mathrm{C} / \mathrm{min}\right)$.

Table 1. Thermal degradation characteristics of LPSQ and POSS-triazole-Py and their precursors.

\begin{tabular}{|c|c|c|c|c|c|c|c|}
\hline \multirow{2}{*}{ Sample } & \multirow{2}{*}{$\mathrm{T}_{\mathrm{d} 1}\left({ }^{\circ} \mathrm{C}\right)$} & \multirow{2}{*}{$\mathrm{T}_{\mathrm{d} 2}\left({ }^{\circ} \mathrm{C}\right)$} & \multicolumn{2}{|c|}{ Rate $\left(\% \cdot \min /{ }^{\circ} \mathrm{C}\right)$} & \multirow{2}{*}{$\mathrm{T}_{5 \%}\left({ }^{\circ} \mathrm{C}\right)$} & \multirow{2}{*}{ Residue (\%) } & \multirow{2}{*}{$\begin{array}{l}\text { Residue Calculated } \\
\text { for } \mathrm{SiO}_{2}(\%)\end{array}$} \\
\hline & & & $\mathbf{V}_{1}$ & $\mathrm{~V}_{2}$ & & & \\
\hline LPSQ-Cl & 382.2 & 509.6 & 2.90 & 1.09 & 358 & 60.2 & 46.2 \\
\hline LPSQ-N 3 & - & - & - & - & 223 & 16.2 & 44.1 \\
\hline LPSQ-triazole-Py & 379.7 & 443.0 & 2.86 & 3.78 & 353 & 30.0 & 16.5 \\
\hline POSS-Cl & 358.2 & 502.1 & 5.56 & 0.63 & 358 & 37.3 & 46.3 \\
\hline POSS-N ${ }_{3}$ & - & - & - & - & 235 & 12.7 & 44.1 \\
\hline POSS-triazole-Py & 376.7 & 434.7 & 2.23 & 1.73 & 352 & 57.5 & 16.6 \\
\hline silane-triazole-Py & 365.3 & 403.0 & 7.35 & 1.11 & 213 & 10.2 & 16.5 \\
\hline
\end{tabular}

$\mathrm{T}_{\mathrm{d}}$-peak temperature of weight loss derivative. $\mathrm{V}$-rate of weight loss at major decomposition step. $\mathrm{T}_{5 \%}-5 \%$ weight loss temperature. residue-char residue at $600{ }^{\circ} \mathrm{C}$. 
Materials with amide-Py groups were less thermally stable than LPSQ-TG. The increasing amount of side amide groups corroborated the observed decrease in $\mathrm{T}_{5 \%}$ (Table 2). The weight loss and the rate of decomposition $\left(\mathrm{V}_{\mathrm{d}}\right)$ during the first decomposition step $\left(\mathrm{T}_{\mathrm{d} 1}=265-300{ }^{\circ} \mathrm{C}\right)$ was higher for materials containing more amide-Py groups (from 20\% wt decrease for LPSQ-amide50-Py to $78 \%$ for LPSQ-amide100-Py) and the char residue at $600{ }^{\circ} \mathrm{C}$ (Figure 3b, Table 2). The opposite situation was observed for the second mass loss stage $\left(\mathrm{T}_{\mathrm{d} 2}=385-470{ }^{\circ} \mathrm{C}\right.$ with weight loss from $30 \%$ for LPSQ-amide50-Py to 4\% for LPSQ-amide100-Py). For POSS-triazole-Py, only one decomposition step was observed (Table 2, Figure S4a), and its $\mathrm{T}_{\mathrm{d}}$ was similar to $\mathrm{T}_{\mathrm{d} 1}$ for LPSQ-amide100-Py $\left(303^{\circ} \mathrm{C}\right.$ with $84 \%$ wt decrease). The lower thermal stability of LPSQ-amide-Py may be explained by decarboxylation of side chains. Such phenomena were observed for carboxylate-functionalized polymers at $250-370{ }^{\circ} \mathrm{C}$ [48]. It corresponds both to the observed $\mathrm{T}_{\mathrm{d} 1}\left(260-300^{\circ} \mathrm{C}\right)$ and the extent of the process illustrated by the peak at $\mathrm{T}_{\mathrm{d}}=360-380^{\circ} \mathrm{C}$.

Table 2. The parameters of thermal degradation of LPSQ and POSS-amide-Py and their precursors.

\begin{tabular}{|c|c|c|c|c|c|c|c|}
\hline \multirow{2}{*}{ Sample } & \multirow{2}{*}{$\mathrm{T}_{\mathrm{d} 1}\left({ }^{\circ} \mathrm{C}\right)$} & \multirow{2}{*}{$\mathrm{T}_{\mathrm{d} 2}\left({ }^{\circ} \mathrm{C}\right)$} & \multicolumn{2}{|c|}{ Rate $\left(\% \cdot \min /{ }^{\circ} \mathrm{C}\right)$} & \multirow{2}{*}{$\mathrm{T}_{5 \%}\left({ }^{\circ} \mathrm{C}\right)$} & \multirow{2}{*}{ Residue (\%) } & \multirow{2}{*}{$\begin{array}{l}\text { Residue Calculated } \\
\text { for } \mathrm{SiO}_{3 / 2}(\%)\end{array}$} \\
\hline & & & $\mathrm{V}_{\mathrm{d} 1}$ & $\mathrm{~V}_{\mathrm{d} 2}$ & & & \\
\hline LPSQ-TG & 279.5 & 362.6 & 1.99 & 3.12 & 262 & 53.1 & 32.0 \\
\hline LPSQ-amide50-Py & 264.8 & 386.9 & 1.89 & 2.53 & 229 & 49.8 & 19.2 \\
\hline LPSQ-amide75-Py & 279.8 & - & 6.36 & - & 233 & 31.9 & 16.4 \\
\hline LPSQ-amide100-Py & 298.6 & 467.0 & 7.52 & 0.25 & 220 & 18.2 & 14.3 \\
\hline POSS-TG & 380.0 & - & 1.72 & - & 190 & 47.1 & 27.8 \\
\hline POSS-amide-Py & 303.4 & - & 7.54 & - & 225 & 20.0 & 13.4 \\
\hline
\end{tabular}

LPSQ-triazole-Py and LPSQ-amide-Py did not show any mesomorphic properties within the studied temperature range. Devitrification was noted only for LPSQ-triazole-Py and POSS-triazole-Py $\left(\mathrm{T}_{\mathrm{g}}=118{ }^{\circ} \mathrm{C}\right.$ and $109{ }^{\circ} \mathrm{C}$, respectively, Figure 4a). POSS-triazole-Py was prepared using POSS- $\mathrm{N}_{3}$ consisting of a mixture of octa-, deca- and dodecahedral species. It is known that physical properties of silsesquioxane cages are determined by the degree of symmetry at the molecular level [49]. POSS systems of different size can form crystalline materials-e.g., pure POSS- $\mathrm{T}_{8}-\mathrm{N}_{3}$ is crystalline, but a mixture of octa-, deca- and dodecasilsesquioxanes is amorphous [41]. Moreover, higher flexibility of $\mathrm{Si}-\mathrm{O}-\mathrm{Si}$ bonds in larger polyhedral cages may also be the cause of the lower crystallinity of these compounds [49]. Highly symmetrical octahedral silsesquioxanes are crystalline (e.g., octakis(3-propyl methacrylate)octasilsesquioxane [49], octakis(3-chloropropyl)octasilsesquioxane [50], octakis(para-nitrobenzene)octasilsesquioxane [51]) but deca- and dodecahedral silsesquioxanes may behave like polymeric materials (e.g., exhibit clear devitrification transitions) $[49,51]$.

LPSQ-TG is a viscous liquid that undergoes devitrification at $-11{ }^{\circ} \mathrm{C}$. Grafting 1-aminopyrene in the side groups reduced flexibility of macromolecules, and $\mathrm{T}_{\mathrm{g}}$ of the obtained LPSQ-amide-Py were found at higher temperatures (Figure $4 \mathrm{~b}$ ). The higher the pyrene moieties grafted along the polymer chains, the higher the observed $\mathrm{T}_{\mathrm{g}}\left(-3^{\circ} \mathrm{C}\right.$ for LPSQ-amide50-Py; $10^{\circ} \mathrm{C}$ for LPSQ-amide75-Py). Glass transition was barely visible for LPSQ-amide100-Py (about $85^{\circ} \mathrm{C}$ ). Octahedral POSS-amide-Py exhibited not only melting at around $\mathrm{T}_{\mathrm{m}}=104^{\circ} \mathrm{C}$ but also a glass transition $\left(\mathrm{T}_{\mathrm{g}}=3{ }^{\circ} \mathrm{C}\right)$ (Figure S5). It may be explained by adjustment of more flexible segments in the crystal structure, analogously to that observed in macromolecular systems [52-54]. 


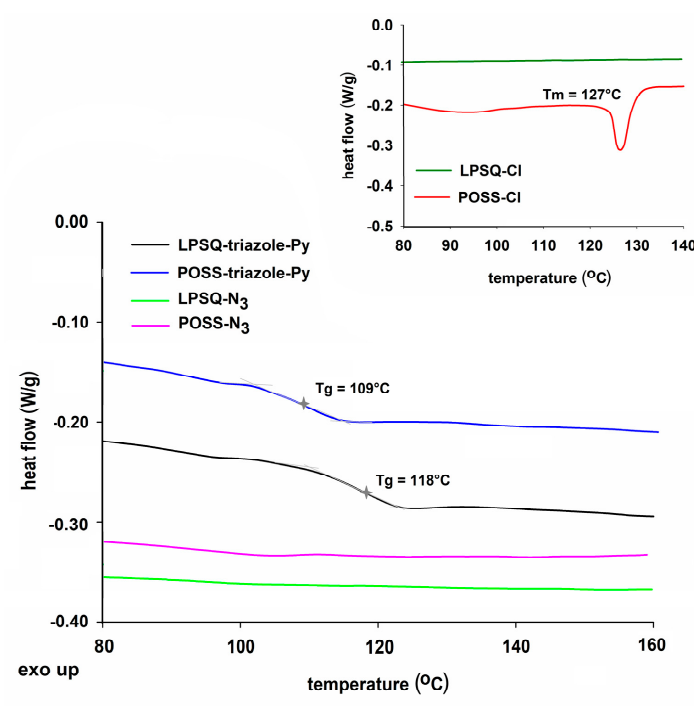

(a)

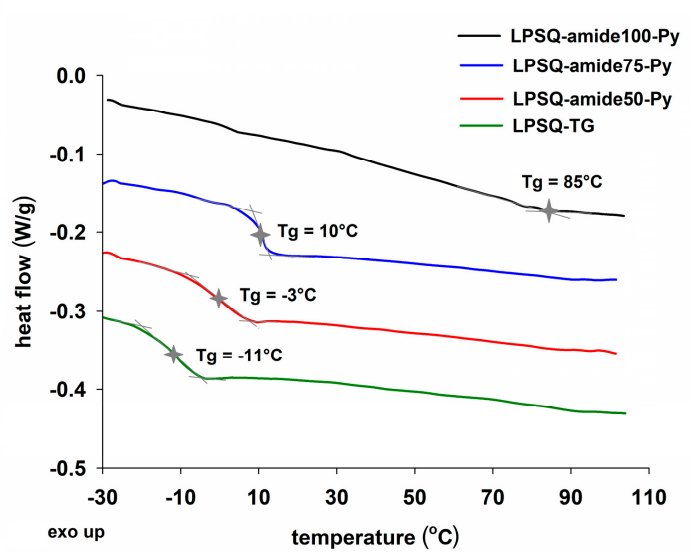

(b)

Figure 4. Thermal analysis of (a) LPSQ and POSS-triazole-Py (inset: LPSQ-Cl and POSS-Cl) (b) LPSQ-amide-Py. DSC traces recorded at a heating rate of $10^{\circ} \mathrm{C} / \mathrm{min}$ (3rd run).

\subsection{Organization of LPSQ and POSS Materials in Solid State}

Good solubility of LPSQ-triazole-Py, LPSQ-amide50-Py and LPSQ-amide75-Py allowed for the preparation of thin films on silicon supports. Solid state organization was studied by wide angle X-ray scattering analysis (WAXS) (Figures 5 and 6). WAXS data revealed differences in the structure of LPSQ, POSS and silane-triazole-Py. The respective diffractograms of LPSQ and POSS show that the materials are amorphous, and three broad peaks with maxima corresponding to $d=3.0,1.2-0.7$ and $0.3 \mathrm{~nm}\left(2 \theta=2.9^{\circ}, 6.7-12.6^{\circ}\right.$ and $\left.28^{\circ}\right)$ can be ascribed to the material organization in the solid state (Figure 5). Such wide diffraction peaks are typical for ladder-like silsesquioxanes [55]. Ladder-like silsesquioxanes can form single crystals only when they have a defined structure, such as the tricyclic ladder-like 1,3,5,5,7,7,9,11,13,13,15,15-cis-cisoid-cis-dodecaisopropyltricyclo[9.5.I.I3,9]octasiloxane [56]. POSS-triazole-Py was a mixture of polyhedral species, and thus, it did not crystallize. The peak with the maximum at around $2 \theta=28^{\circ}(0.3 \mathrm{~nm})$ may be correlated with $\mathrm{Si}-\mathrm{O}-\mathrm{Si}$ bonds. According to our HyperChem calculations, signals found for LPSQ-triazole-Py at around 3 and $1.2 \mathrm{~nm}\left(2 \theta=2.9^{\circ}\right.$ and $\left.6.7^{\circ}\right)$ may correspond to the ladder width and approximate size of the side group, respectively. Differences between diffraction patterns of LPSQ and POSS result from different packing of the substituents around the inorganic core and different organization of pyrene groups in the solid state. WAXS analysis of silane-triazole-Py indicate that the material is partially crystalline (Figure S6a). A set of sharp diffraction peaks with maxima corresponding to $\mathrm{d}=2.8,1.5$ and $0.75 \mathrm{~nm}\left(2 \theta=3.1^{\circ}, 6^{\circ}\right.$ and $\left.12.8^{\circ}\right)$ appeared. The signal at $2 \theta=6^{\circ}(\mathrm{d}=1.5 \mathrm{~nm})$ may be assigned to the size of silane-triazole-Py molecules, and the peak around $\mathrm{d}=2.8 \mathrm{~nm}\left(2 \theta=3^{\circ}\right)$ may be connected with the formation of $\pi$-stacks due to the $\pi-\pi$ interactions between aromatic rings $[57,58]$. 


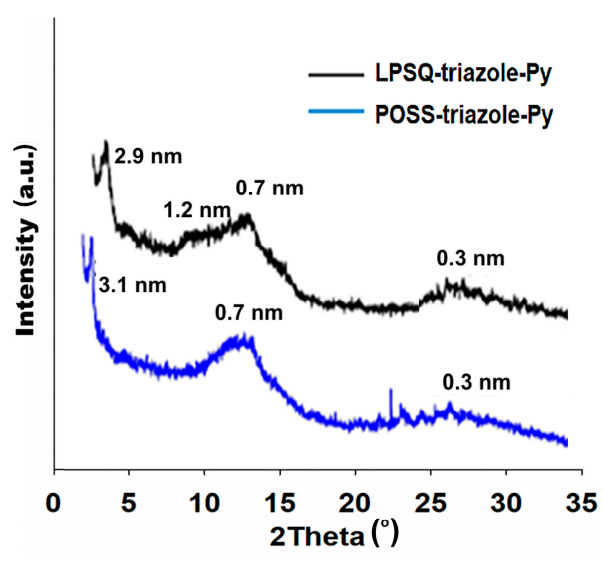

(a)

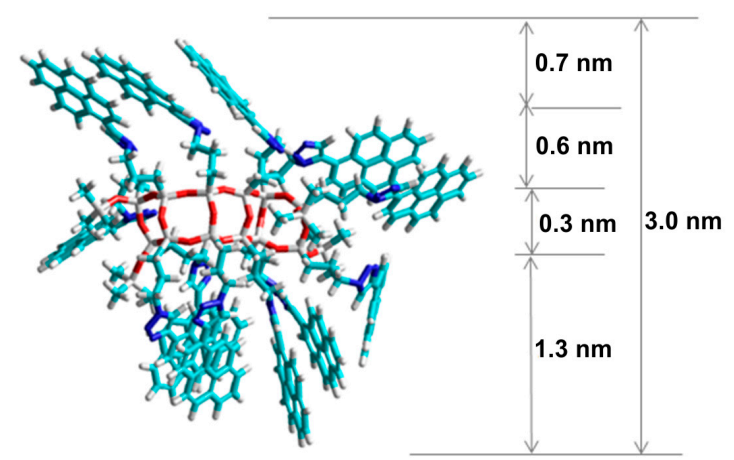

(b)

Figure 5. (a) WAXS diffractograms of thin films of LPSQ and POSS-triazole-Py. (b) HyperChem calculated structure for LPSQ-triazole-Py.

The surface structure of thin films of LPSQ, POSS and silane-triazole was analyzed with AFM (Figure 7 and Figure S6b). The thin films covered the support completely. Layers formed by LPSQ-triazole-Py exhibited high regularity. Macromolecules were arranged in an oriented manner with an average distance between lamellae around $24 \mathrm{~nm}$. The periodicity was confirmed by Fast Fourier Transform (FFT) of the AFM image that is often used to eliminate periodic noise from AFM images with repetitive patterns [59-61]. The periodicity can be connected with strong interchain interactions between pyrene molecules in the side chains. The film made of POSS-triazole-Py had an irregular structure, indicating formation of agglomerates. A similar difference in the structure of thin films was reported by us for LPSQ-Py and POSS-Py [30]. Silane-triazole-Py formed flat films of constant thickness (2.2 nm) (Figure S6b).

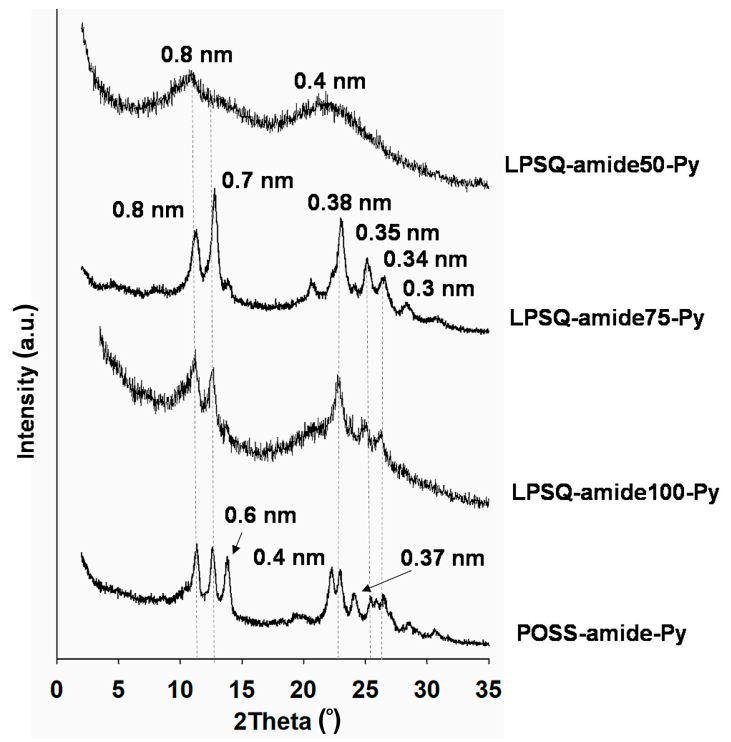

(a)

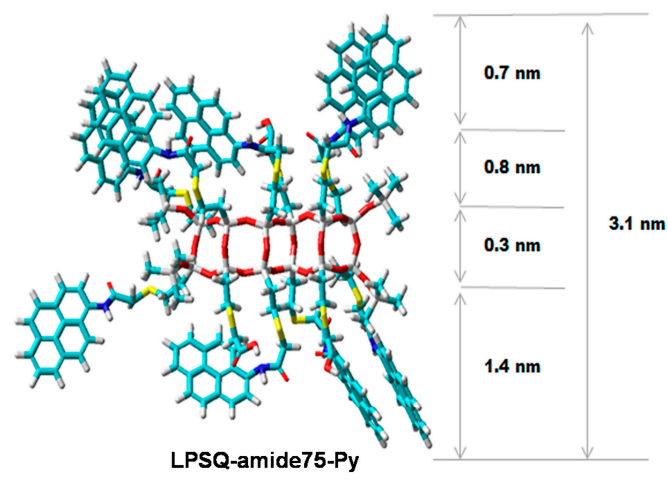

(b)

Figure 6. (a) WAXS diffractograms of thin films of LPSQ-amide-Py and POSS-amide-Py cast on silicon plates from DMF solutions; (b) HyperChem [37] calculated structure for LPSQ-amide75-Py. 

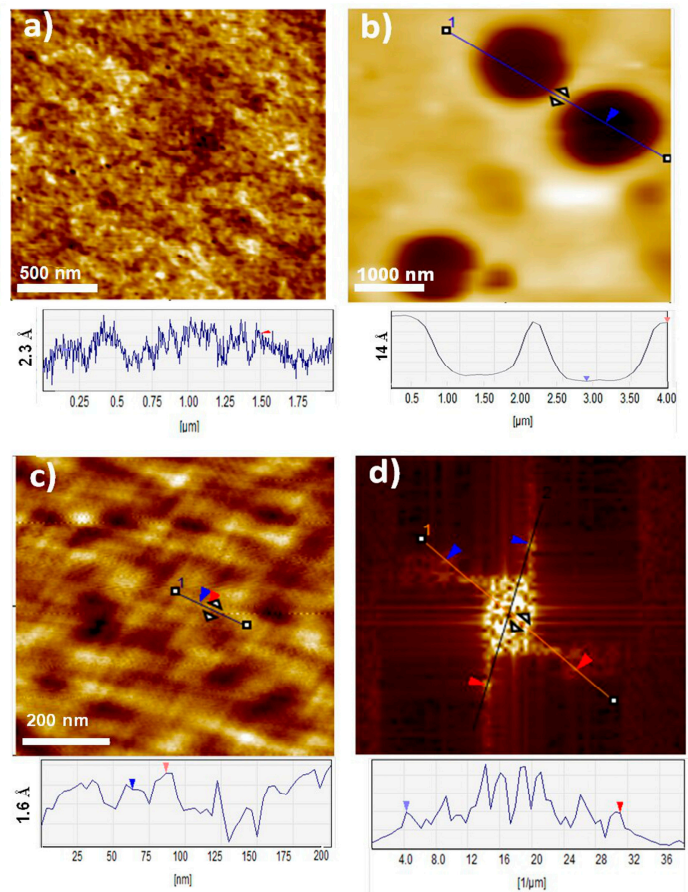

Figure 7. Atomic force microscopy height images and cross-sectional analysis of (a) LPSQ-triazole-Py; (b) POSS-triazole-Py thin films cast on silicon supports; (c) LPSQ-triazole-Py image after (d) FFT spectrum analysis.

Thin films of LPSQ and POSS-amide-Py were prepared by drop casting of the respective DMF solutions on silicon supports. Reflected light microscopy images of LPSQ-amide75-Py revealed formation of fiber-like crystalline structures (Figure 8a). AFM analysis of the top layer of crystals revealed a certain periodicity (Figure 8b). Formation of thin twisted fibers of helical structure was also reported for LPSQ-Py [30]. LPSQ-amide50-Py and POSS-amide-Py formed large needle-like structures (length 150-200 $\mu \mathrm{m}$ ) (Figure S7). This can be explained by aggregation of macromolecules during slow solvent evaporation resulting in the formation of well-organized crystals. In the case of POSS-amide-Py, the needle-like structures were present on the top of a crystalline base layer that covered the support. The morphology of amide containing silsesquioxanes was also studied by X-ray diffraction (Figure 6). Differences between diffraction patterns of LPSQ and POSS-amide-Py illustrate different organization of side groups in the solid state. This may be related to the amount of hydrogen bonds between side chains. The content of amide bonds in LPSQ-amide50-Py is too low to interconnect the side chains by hydrogen bonds. This product is amorphous, and its WAXS analysis exhibits only two wide peaks with maxima around 0.8 and $0.4 \mathrm{~nm}\left(2 \theta=11^{\circ}\right.$ and $\left.22^{\circ}\right)$, that are typical for linear oligo(silsesquioxanes) with simple alkyl or aryl groups. Diffractograms of other products indicate their partial crystallinity. Analyses revealed multiple peaks corresponding to interplanar spacing $\mathrm{d}=0.8,0.7,0.38,0.35,0.34$ and $0.30 \mathrm{~nm}\left(2 \theta=11^{\circ}, 12.6^{\circ}, 23.2^{\circ}, 25.8^{\circ}, 26.5^{\circ}\right.$ and $\left.28^{\circ}\right)$ (Figure 6). Peaks around $2 \theta=11^{\circ}(\mathrm{d}=0.8 \mathrm{~nm})$ correspond to the length of linkers between pyrene molecules and LPSQ main chain or POSS core. Peaks around $2 \theta=12.6^{\circ}(\mathrm{d}=0.7 \mathrm{~nm})$ can be associated with the size of pyrene moieties or distance between adjacent side substituents. Signals in the range $0.34-0.38 \mathrm{~nm}\left(2 \theta=23.2-26.5^{\circ}\right)$ might be related to the interplanar $\pi-\pi$ distance between Py moieties [57,62]. LPSQ-amide75-Py contains an optimal amount of amide groups to obtain a good arrangement of side substituents for association by both hydrogen bonds and $\pi-\pi$ interactions. The high degree of regularity in thin layers allowed us to obtain a diffractogram which shows intense peaks associated with the structure of LPSQ-amide75-Py. As could be expected, almost all side chains in LPSQ-amide100-Py were associated by the formation of hydrogen bonds. It significantly rigidified the entire macromolecule. A tight network of hydrogen bonds between the side substituents was already present in solutions used for the preparation of thin 
films that were analyzed with WAXS. The high content of side substituents with high steric hindrance, the presence of hydrogen bonds and $\pi-\pi$ interactions leave less free space for an effective arrangement of all the side substituents. All peaks characteristic for LPSQ-amide-Py are present, but due to the lower degree of order, their intensity is quite low. WAXS analysis of POSS-amide-Py exhibited additional peaks corresponding to $\mathrm{d}=0.6,0.4$ and around $0.37 \mathrm{~nm}\left(2 \theta=14.7^{\circ}, 22^{\circ}\right.$ and $\left.23.8^{\circ}\right)$.

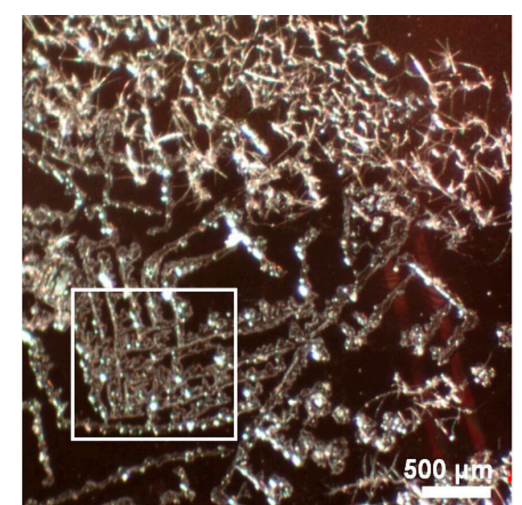

(a)

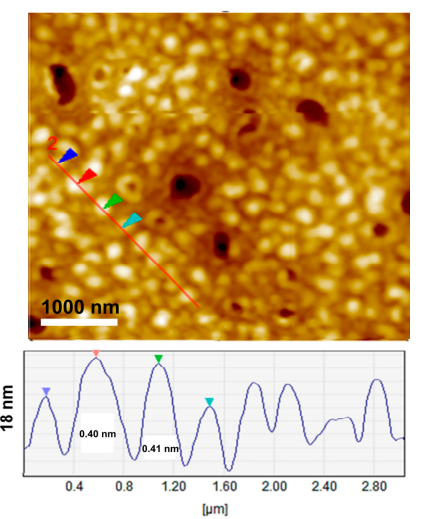

(b)

Figure 8. (a) Reflected light micrographs and (b) atomic force microscopy image and cross-section of LPSQ-amide75-Py crystals. AFM image shows the top of a typical crystal surface in the area marked with the white frame.

\subsection{Optical and Photophysical Properties-Comparison of LPSQ/POSS-Triazole and LPSQ-POSS-Amide}

Optical and photophysical properties of the prepared LPSQ and POSS with pyrene moieties in side chains were studied at room temperature with UV-Vis and fluorescence spectroscopy in diluted solutions ( $c=10^{-8}-10^{-3} \mathrm{~mol} / \mathrm{L}$ of Py units) and in the solid state. Both LPSQ and POSS bearing pyrene moieties in their side chains did not have clear-structured absorption bands-typical for small molecules. The absorption spectra of LPSQ and POSS are similar and consist of a single, wide band with only one maximum for LPSQ/POSS-triazole-Py (Figure 9a and Figure S8) and three maxima for LPSQ/POSS-amide-Py (Figure 9c and Figure S9). Such broad absorption bands suggest pre-association of chromophores in the ground state and the presence of self-assembled structures even in extremely diluted solutions $\left(\mathrm{c}_{\mathrm{Py}}=10^{-8} \mathrm{~mol} / \mathrm{L}\right)$ [63].

The steady-state fluorescence measurements were carried out using the excitation wavelengths of the $S_{0} \rightarrow S_{2}$ transitions (387 nm for solutions of LPSQ/POSS-amide-Py derivatives in DMF and $350 \mathrm{~nm}$ for solutions of LPSQ/POSS-triazole-Py in $\mathrm{CHCl}_{3}$ and THF). The structure of silsesquioxanes has a strong effect on their fluorescence (Figure 9b,d, Figure S9 and Figure 10). FL spectra of dilute solutions of LPSQ and POSS-triazole-Py (both in THF and $\mathrm{CHCl}_{3}$ ) exhibited almost exclusively a bright green excimer emission band with a maximum around $487 \mathrm{~nm}$. In contrast, FL emission spectra obtained for the model silane-triazole-Py consist mostly of strong pyrene monomer emission and almost did not exhibit the excimer emission, even at $\mathrm{C}_{\mathrm{Py}}=10^{-3} \mathrm{~mol} / \mathrm{L}$. The presence of $\mathrm{T}_{8}$, $\mathrm{T}_{10}$ and $\mathrm{T}_{12}$ in the POSS-triazole-Py should not influence optical properties of the studied material. The three-dimensional structure of POSS, regardless of their size, does not facilitate interactions between Py substituents. The side chains have much more freedom to move around the POSS core, which leads to the predominant influence of the $\pi-\pi$ interactions between Py moieties. 


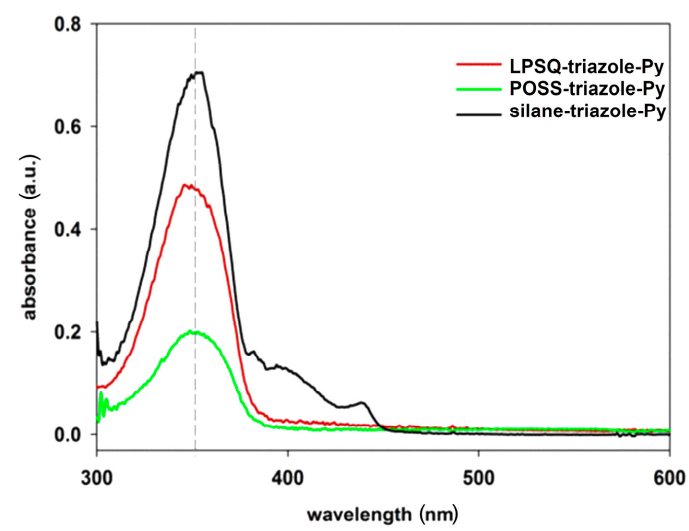

(a)

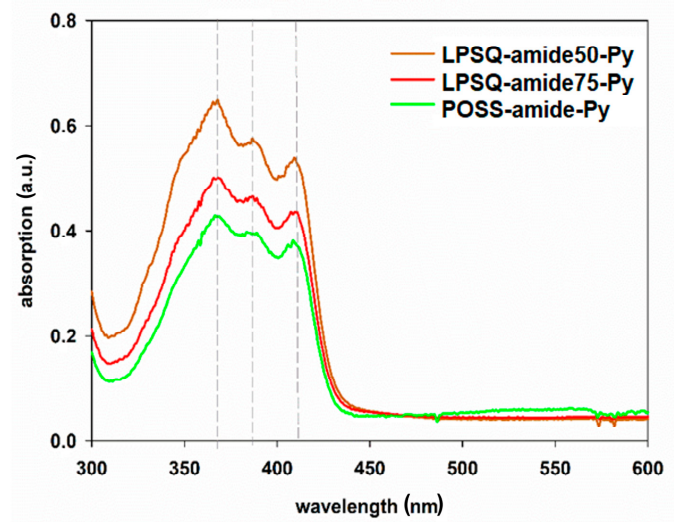

(c)

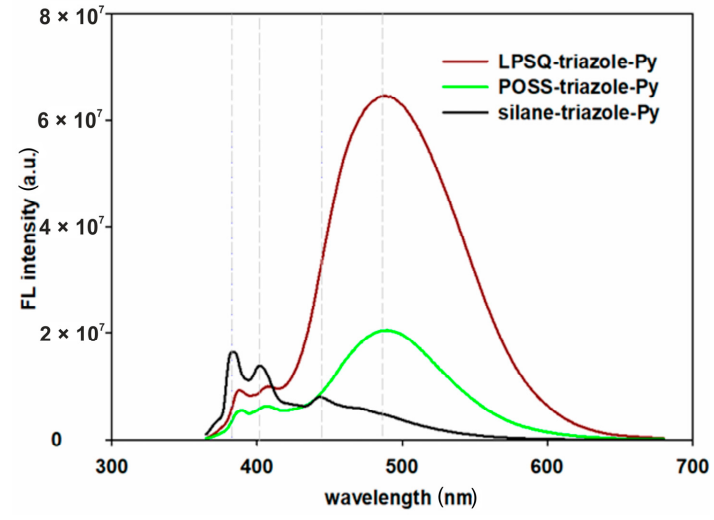

(b)

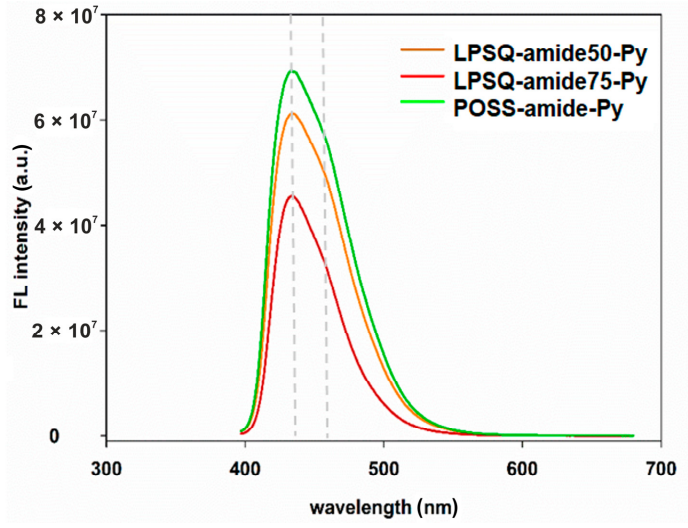

(d)

Figure 9. Comparison of (a) absorption and (b) FL emission spectra $\left(\lambda_{\mathrm{ex}}=350 \mathrm{~nm}\right)$ of LPSQ, POSS, silane-triazole $\left(\mathrm{c}_{\mathrm{Py}}=10^{-6} \mathrm{~mol} / \mathrm{L}\right.$ in THF), (c) absorption and (d) FL emission spectra $\left(\lambda_{\mathrm{ex}}=387 \mathrm{~nm}\right)$ of LPSQ-amide50-Py, LPSQ-amide75-Py and POSS-amide-Py ( $\mathrm{c}_{\mathrm{Py}}=10^{-6} \mathrm{~mol} / \mathrm{L}$ in DMF).

Traces of monomeric vibronic bands could be observed in all solutions of LPSQ and POSS-triazole-Py in (THF and $\left.\mathrm{CHCl}_{3}\right)$. The ratio of excimer $\left(\mathrm{I}_{\mathrm{EXC}}\right)\left(\lambda_{\mathrm{EXC}}=490 \mathrm{~nm}\right)$ and monomer $\left(\mathrm{I}_{\mathrm{MON}}\right)\left(\lambda_{\mathrm{MON}}=407 \mathrm{~nm}\right)$ FL emission intensity is 3-4 times higher for LPSQ-triazole-Py (Figure 10a), which can be ascribed to different geometry of the inorganic structures and associated orientation of the pyrene moieties. High intensity of the excimer emission band in the most diluted solutions of LPSQ-triazole-Py points to its intramolecular nature due to the congestion of chromophores along the polymer chain. The increase in Py concentration resulted in a slight bathochromic shift of $\lambda_{\text {EXC }}$ from $487 \mathrm{~nm}$ to $490 \mathrm{~nm}$.

FL emission intensity of LPSQ derivative is more than twice as high as that of POSS (Figure 10b and Figure S10). FL quenching occurred at a similar concentration for both silsesquioxanes (at $\mathrm{c}_{\mathrm{Py}} \geq 5 \times 10^{-5} \mathrm{~mol} / \mathrm{L}$ ). No solvent effect was observed concerning the intensity and shape of FL emission bands of LPSQ and POSS-triazole-Py. 


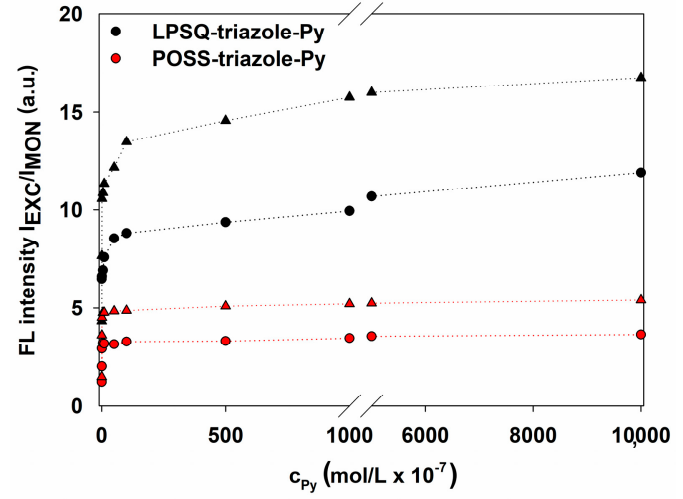

(a)

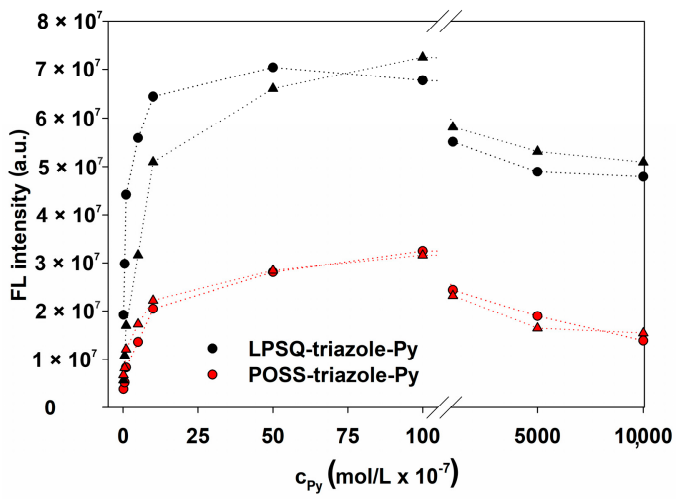

(b)

Figure 10. Comparison of fluorescence emission intensity (a) ratio $\mathrm{I}_{\mathrm{EXC}} / \mathrm{I}_{\mathrm{MON}}$ and (b) $\mathrm{I}_{\mathrm{EXC}}$ as a function of pyrene groups concentration ( $\bullet$ in THF, $\Delta$ in $\mathrm{CHCl}_{3}$; black for LPSQ, red for POSS).

The excitation spectra of LPSQ and POSS-triazole-Py in THF were recorded at the emission wavelength of the excimer $\left(\lambda_{\mathrm{EXC}}=490 \mathrm{~nm}\right)$ (Figure 11a,b). The observed degree of correlation with the respective absorption spectra was almost identical for LPSQ and POSS. Excitation spectra were also recorded at $\lambda=390,407,428$ and $490 \mathrm{~nm}$ (Figure 11a,b). Their overlap was exact for LPSQ-triazole-Py. This result indicates the dynamic nature of the excimer [64,65]. Similar results were obtained for POSS-triazole-Py.

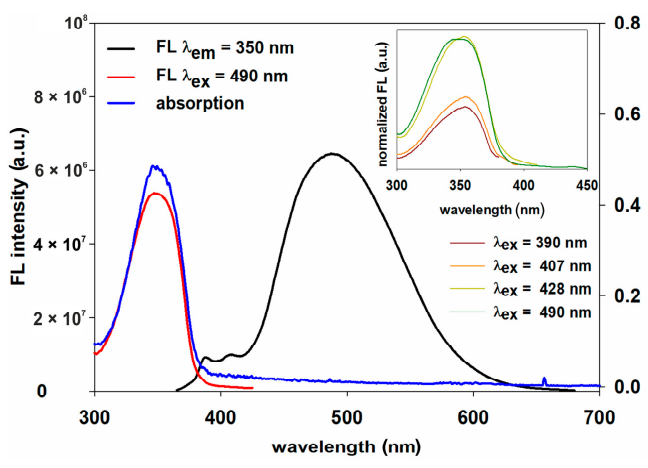

(a)

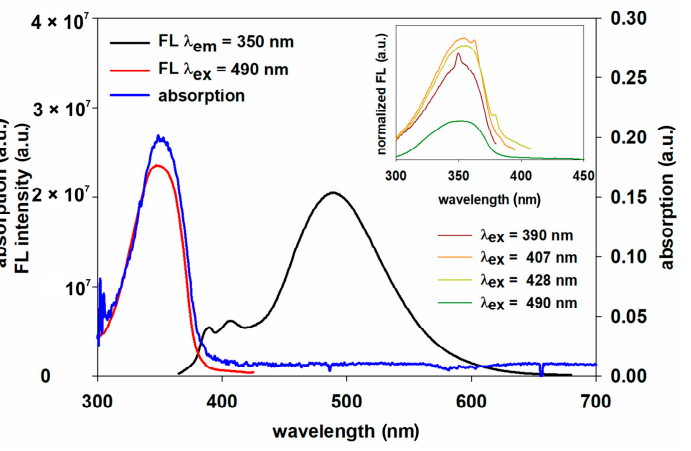

(b)

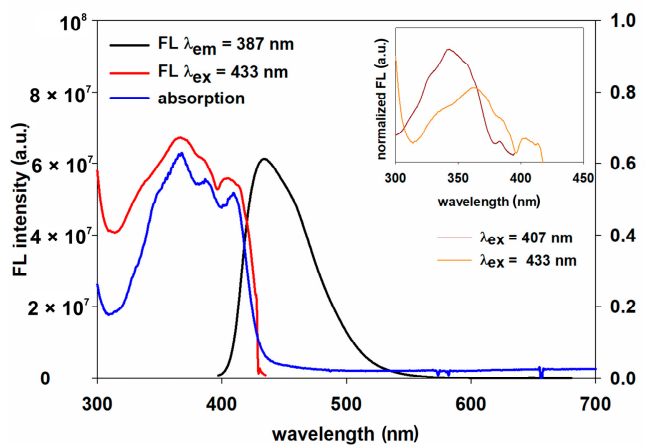

(c)

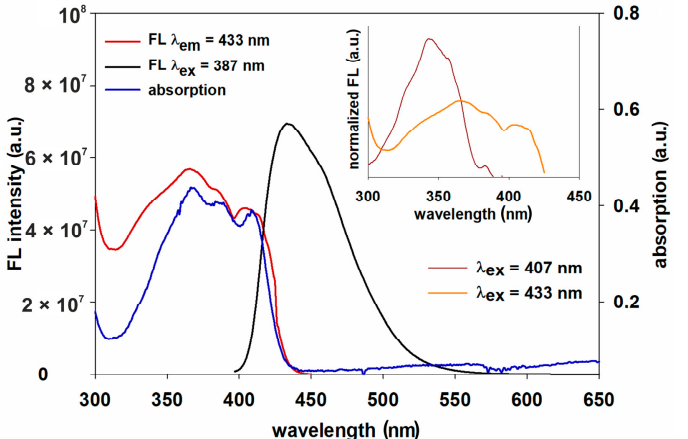

(d)

Figure 11. Emission and excitation fluorescence spectra with absorbance spectra of (a) LPSQ-triazole-Py, (b) POSS-triazole-Py (in THF) and (c) LPSQ-amide50-Py, (d) POSS-amide-Py (in DMF). All measurements for solutions at $\mathrm{c}_{\mathrm{Py}}=10^{-6} \mathrm{~mol} / \mathrm{L}$.

FL spectra of dilute solutions of LPSQ and POSS-amide-Py in DMF exhibited exclusively a bright emission band with a maximum at $433 \mathrm{~nm}$ (Figure 9d and Figure S9). High intensity of this emission band, even in the most diluted solutions, suggests the intramolecular nature of excimers due to 
the congestion of chromophores along the polymer chain. The shape of FL emission bands of all materials bearing amide groups in their side chains is very similar. Spectra with a maximum of FL emission intensity at $\sim 430 \mathrm{~nm}$ was previously reported for various pyrene-1-carboxamides $[66,67]$. The decrease in fluorescence intensity with the increase in concentration in solution occurred more rapidly for LPSQ-amide50-Py ( $\mathrm{C}_{\mathrm{Py}} \geq 10^{-6} \mathrm{~mol} / \mathrm{L}$ ) than for LPSQ-amide75-Py and POSS-amide-Py $\left(\mathrm{C}_{\mathrm{Py}} \geq 5 \times 10^{-5} \mathrm{~mol} / \mathrm{L}\right)$ (Figure 12). this can be explained by a more pronounced influence of intermolecular interactions for LPSQ-amide50-Py.

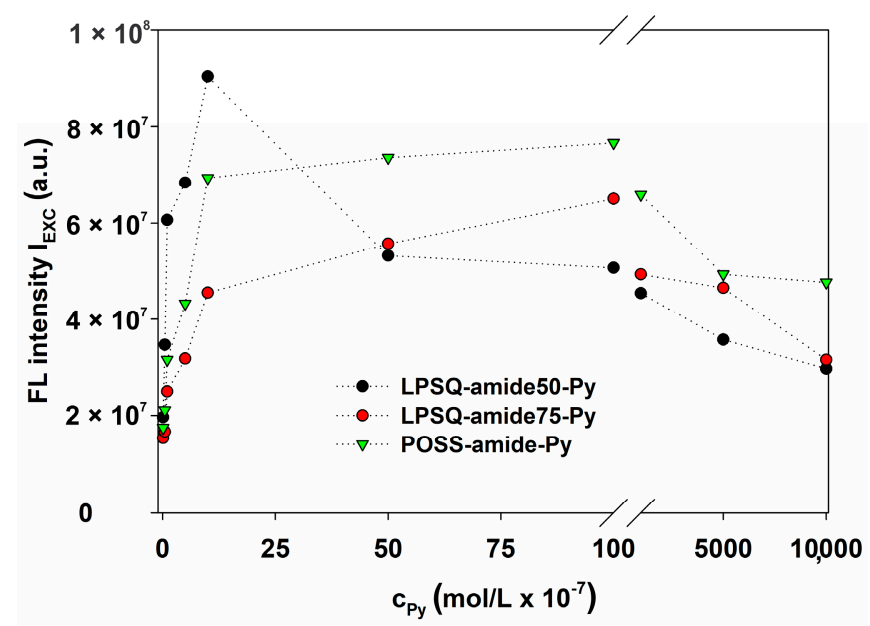

Figure 12. Changes in fluorescence excimer intensity as a function of pyrene moieties concentration $\left(\lambda_{\mathrm{ex}}=430 \mathrm{~nm}\right)$.

The excitation spectra of LPSQ and POSS-amide-Py in DMF were recorded at the wavelength $\lambda_{\mathrm{em}}=433 \mathrm{~nm}$ that responded to the maximum of FL emission intensity (Figure 11c,d and Figure S11). Excitation spectra were also recorded in DMF at the emission wavelength of $407 \mathrm{~nm}$. The observed degree of correlation with the respective absorption spectra was very similar. They do not overlap which suggests that observed excimers for LPSQ and POSS-amide-Py are static in nature and their formation is not dependent on the diffusion or the solution concentration [68].

Despite the structural differences, both LPSQ and POSS-triazole-Py are emissive in the solid state (Figure 13a). The much stronger intensity of LPSQ-triazole-Py FL emission than that of the POSS counterpart can be ascribed to the stronger interactions between pyrene moieties along the linear chains than around 3D inorganic cores of the polyhedral compound. The $\lambda_{\max }$ in the FL spectrum of LPSQ-triazole-Py is blue shifted in comparison to POSS-triazole-Py which illustrates the difference in supramolecular organization of Py moieties in the solid state for both materials. Differences in the FL emission $\lambda_{\max }$ were previously observed for LPSQ-Py and POSS-Py [30]. For the studied silsesquioxane derivatives containing amide groups, LPSQ-amide100-Py and LPSQ-amide75-Py exhibited the highest FL emission intensity (Figure 13b). The observed differences in the FL emission intensity of LPSQ-amide100-Py and POSS-amide-Py were similar to the FL emission intensity of LPSQ and POSS-triazole-Py. LPSQ-amide50-Py exhibited the lowest FL emission intensity (Figure 13b). 


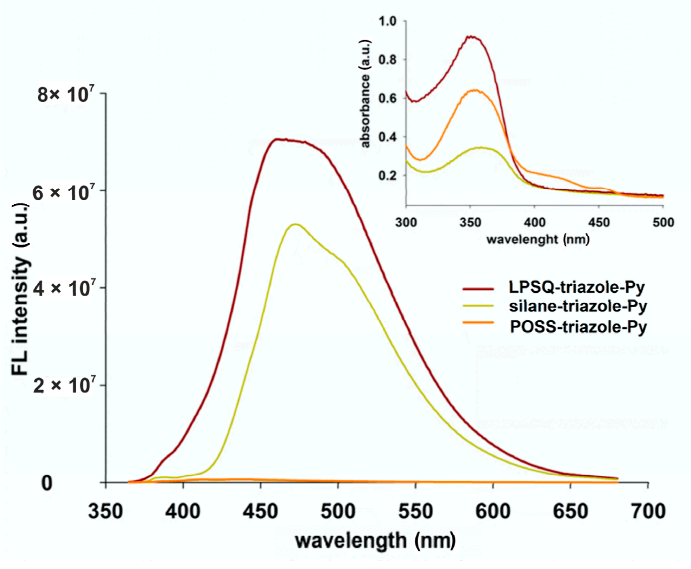

(a)

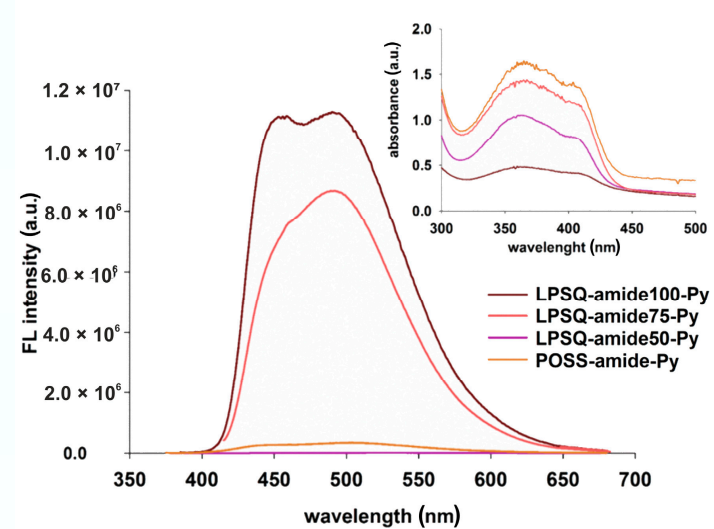

(b)

Figure 13. FL and absorption spectra for thin films of LPSQ and POSS materials containing (a) triazole and (b) amide groups in side substituents.

\subsection{Energy Transfer with LPSQ-Triazole-Py and LPSQ-Amide-Py}

The efficiency of fluorescence resonance energy transfer depends on the distance between donor and acceptor molecules and the overlap of the emission spectrum of the donor and the absorbance spectrum of the acceptor. It is thus important to choose spectrally suitable species to transfer energy from green-emitting pyrene excimers. Organic dyes such as 9-diethylamino-5-benzo[ $\alpha]$ phenoxazinone (Nile Red, NR) and 3-(1,3-Benzothiazol-2-yl)-7-(diethylamino)-2H-chromen-2-one (Coumarin 6, Cou) are suitable for such artificial energy transfer systems [69-72].

We found that macromolecules of LPSQ-triazole-Py were able to act as energy donors to red-emitting Nile Red (Figure 14a). As required for an efficient resonance transfer of energy, the emission of LPSQ-triazole-Py overlaps well with the absorption spectrum of $\mathrm{NR}$ in solution in $\mathrm{CHCl}_{3}$. Excitation at $350 \mathrm{~nm}$ involved mainly Py excimers, and the NR acceptor emission was observed with a decrease in the Py excimer emission due to fluorescence resonance energy transfer. A slight change in the shape of the Py excimer emission band was also noted with increasing NR concentration in the mixture. This suggests a selective fluorescence resonance energy transfer from a defined range of spectrally suitable excimers. The fluorescence resonance energy transfer was also studied from POSS-triazole-Py to NR (Figure S12a). The size of POSS should not affect EnT, so all tests were carried out on the prepared mixture of POSS $-\mathrm{T}_{8}-\mathrm{N}_{3}$, POSS $-\mathrm{T}_{10}-\mathrm{N}_{3}$ and POSS- $\mathrm{T}_{12}-\mathrm{N}_{3}$ (POSS-triazole-Py). Due to the small degree of overlapping between FL emission spectra of amide containing LPSQ and NR absorption bands, the energy transfer in this system occurred only to a very small extent (Figure 15a).

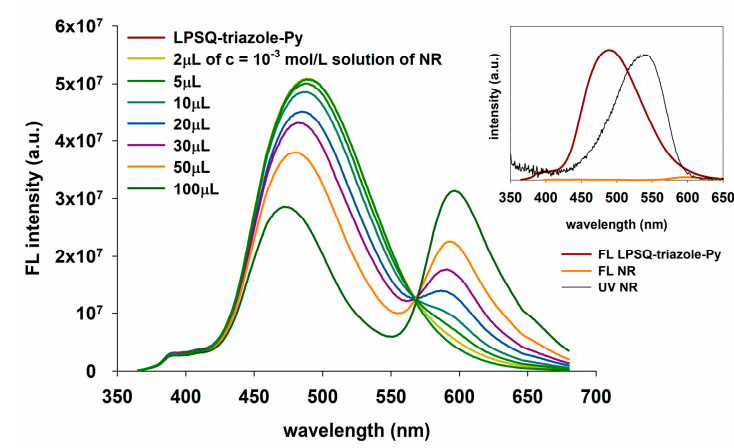

(a)

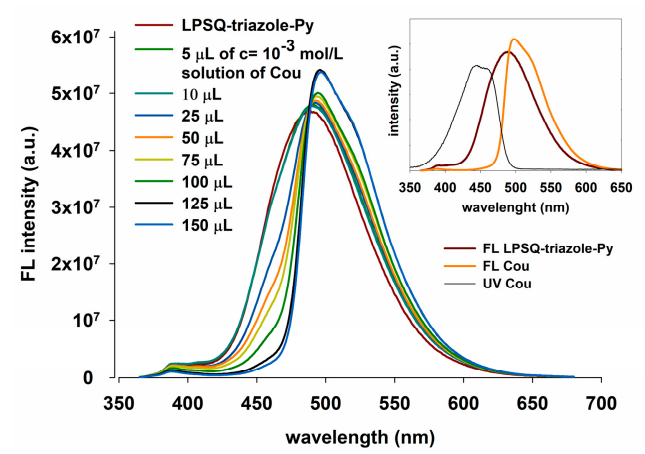

(b)

Figure 14. Energy transfer from LPSQ-triazole-Py to (a) Nile Red and (b) Coumarin 6 (insets: spectral overlap of LPSQ derivatives and dyes; measurements carried out as described in Materials and Methods). 


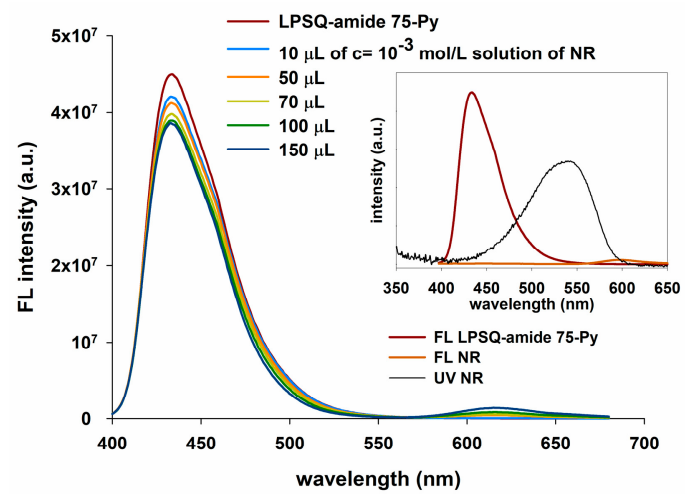

(a)

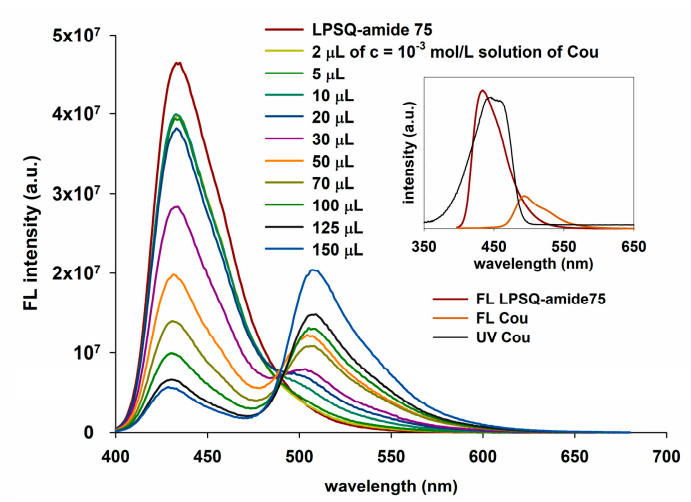

(b)

Figure 15. Energy transfer from LPSQ-amide75-Py to (a) Nile Red and (b) Coumarin 6 (insets: spectral overlap of LPSQ derivatives and dyes; measurements as described in Materials and Methods).

Coumarin 6 was also tested for the resonance energy transfer from Py excimers in LPSQ-triazole (Figure 14b), LPSQ-amide50 (Figure S13a) and LPSQ-amide75 (Figure 15b). The characteristic emission of Cou increased with quenching of the pyrene excimer band. The obtained results suggest the existence of a pathway for fluorescence resonance energy transfer from LPSQ-triazole-Py and LPSQ containing side amide groups to the acceptor dye. A decrease in FL emission intensity was observed for LPSQ-triazole-Py, LPSQ-amide50-Py and LPSQ-amide75-Py in the presence of Cou, but only for amide containing LPSQ, it was accompanied by an increase in Cou FL intensity. The degree of overlapping of FL emission bands of LPSQ-amide-Py and Cou was higher than that observed in the case of POSS-triazole-Py, but IEXC of LPSQ-amide-Py was also around three times higher than that of Cou, when excited at $\lambda=387 \mathrm{~nm}$. FL emission intensities of Cou and LPSQ-triazole-Py were very similar when excited at $\lambda=350 \mathrm{~nm}$. In this case, the characteristic emission of Cou increased with quenching of the LPSQ-triazole-Py excimer band, but those two overlapped extensively and changes in the intensity of the former were not easy to notice. Different maxima of FL emission of Cou and LPSQ-amide-Py additionally facilitated the observation of fluorescence emission energy transfer.

\subsection{Cation Sensing Ability of the Hybrid Silsesquioxanes}

The fluorescent nature of all the prepared materials was also explored for detection of paramagnetic $[\mathrm{Cu}(\mathrm{II}), \mathrm{Fe}(\mathrm{III}), \mathrm{Co}(\mathrm{II})]$ and diamagnetic [Ag(I), $\mathrm{Hg}$ (II), $\mathrm{Mg}(\mathrm{II}), \mathrm{Ca}(\mathrm{II}), \mathrm{Pb}(\mathrm{II}), \mathrm{Zn}$ (II)] cations. Metal ions influence properties of molecules containing heteroatoms and play an important role in many biological processes [72,73]. Interactions of paramagnetic cations with $\pi$ electrons of pyrene moieties have previously been exploited in fluorescent sensing systems [74-78]. We conducted comparative studies on the sensitivity and selectivity of cation detection on the basis of the fluorescence response with an individual addition of diverse perchloric (VII) acid salts to solutions of LPSQ/POSS-amide-Py (in DMF) and LPSQ/POSS-triazole-Py (in THF) (Figure 16, Figures S14 and S15). The size of POSS and the content of prepared product mixture should not affect its optical properties in the presence of cations; all tests were carried out on the prepared mixture of POSS- $\mathrm{T}_{8}-\mathrm{N}_{3}$, POSS- $\mathrm{T}_{10}-\mathrm{N}_{3}$ and POSS- $\mathrm{T}_{12}-\mathrm{N}_{3}$ (POSS-triazole-Py).

The fluorescence intensity of LPSQ-amide50-Py, LPSQ-triazole-Py and POSS-triazole-Py noticeably decreased with the addition of paramagnetic cations: $\mathrm{Cu}$ (II) and $\mathrm{Fe}(\mathrm{III})$ and $\mathrm{Co}$ (II). Changes in FL emission intensity were also observed for triazole-containing materials in the presence of diamagnetic $\mathrm{Ag}$ (I) and $\mathrm{Hg}$ (II) ions. Sensing ability of pyrene derivatives toward $\mathrm{Cu}$ (II) and $\mathrm{Fe}(\mathrm{III})$ stems from, respectively, reverse-PET phenomenon $[79,80]$ and electron transfer from the excited Py chromophores [81]. Py FL quenching in the presence of $\mathrm{Ag}(\mathrm{I})$ and $\mathrm{Hg}(\mathrm{II})$ can be explained by the heavy atom effect [79]. 
While the studied triazole-containing materials exhibited high sensing ability toward cations, the change in FL intensity for LPSQ-amide75-Py was influenced only slightly. This may be explained in terms of strong hydrogen bonds between the side substituents that make Py chromophores better packed and less accessible for metal cations. Indeed, LPSQ-amide50-Py detected the presence of Cu(II), $\mathrm{Fe}(\mathrm{III})$ and $\mathrm{Co}(\mathrm{II})$, although the effect was not large. Interestingly, POSS-amide-Py exhibited FL emission quenching only in the presence of $\mathrm{Co}$ (II) ions (Figure S15a,b). The highest sensitivity of POSS-amide-Py toward $\mathrm{Co}$ (II) cations can be explained by low steric hindrance and easy accessibility to amide groups in side chains around the POSS core. Cobalt is among the essential trace elements and plays a crucial role in biological systems [82], but it is toxic at a high level [83], and thus, sensitive methods of its detection are needed. Compounds containing amide, amine and carboxyl groups were proposed as possible molecular colorimetric or fluorescent probes based on photoinduced electron transfer (PET) or chelation-enhanced fluorescence due to their ability to coordinate $\mathrm{Co}$ (II) [84,85]. It may be expected that $\mathrm{Co}(\mathrm{II})$ is also complexed by amide bonds in neighboring side groups of POSS-amide-Py, but the sensing mechanism rather involves the excimer fluorescence quenching.

The difference in sensitivity of LPSQ-triazole-Py and LPSQ-amide50-Py is presented in Figure 16a. The photographs show dramatic fluorescence emission changes of LPSQ-triazole-Py in the presence of $\mathrm{Cu}$ (II) ions (under UV lamp). In contrast, almost no visible change in FL emission intensity of LPSQ-amide50-Py and LPSQ-amide75-Py was observed (Figure 16b). It is possible that sensitivity of materials was influenced by the properties of chosen solvent. A highly polar medium may strengthen $\pi-\pi$ interactions between aromatic moieties and thus hinder $\mathrm{M}^{\mathrm{n}+}-\pi$ interactions [86]. DMF applied as a solvent for amide containing silsesquioxanes exhibits much higher polarity $(\varepsilon=38, \mathrm{D}=3.82)$ than THF ( $\varepsilon=7.5, \mathrm{D}=1.75)$ used for studies with LPSQ/POSS-triazole-Py. This might affect the influence of metal cations on FL emission intensity.

Studies on the selectivity of FL emission quenching in the presence of mixtures of various cations appear very interesting; therefore, we intend to carry out such tests in the next stage of our research on new optically active materials.

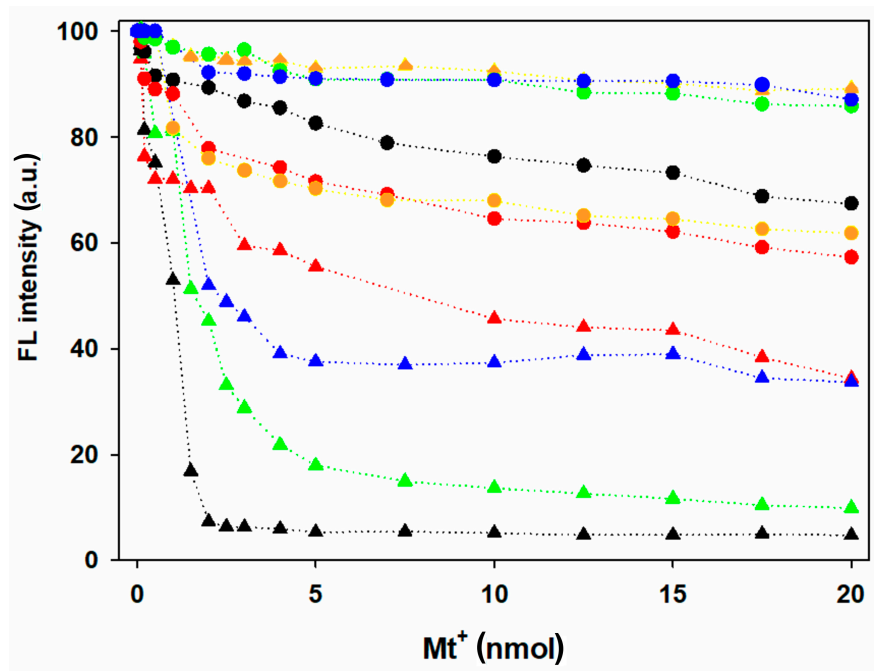

(a)

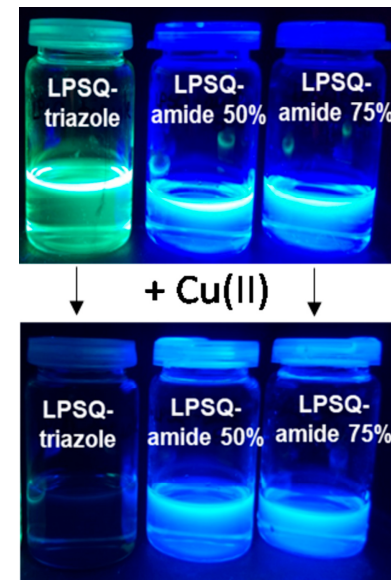

(b)

Figure 16. (a) Comparison of FL emission intensity of $\Delta$-LPSQ-triazole-Py (in THF) and --LPSQ-amide50-Py (in DMF) in the presence of perchloric (VII) acid salts; (b) visible changes of FL emission intensity of LPSQ-triazole-Py, LPSQ-amide50-Py and LPSQ-amide75-Py in the presence of $\mathrm{Cu}(\mathrm{II})$ ions $\left(\mathrm{n}_{\mathrm{Cu}(\mathrm{II})}=\mathrm{n}_{\mathrm{Py}}\right)$. 


\section{Conclusions}

Pyrene chromophores were grafted onto hybrid silsesquioxane macromolecules of various morphologies by means of Hüisgen coupling or amide bond formation. The unique architecture of linear, ladder-like poly(silsesquioxanes) bearing Py moieties in side chains favors the formation of intramolecular excimers, both in very diluted solutions and in the solid state. The observed optical properties depend on the structure of silsesquioxane framework (linear or polyhedral), spacing between chromophores, morphology of linkers between pyrene moieties and polymer backbone and restriction of their motion. The formation of hydrogen bonds between the spacers containing amide bonds and linking Py substituents to the inorganic backbone determined optical and physicochemical properties of LPSQ-amide-Py.

It was found that LPSQ-triazole-Py and LPSQ-amide-Py are capable of an efficient fluorescence resonance energy transfer to suitable red-emitting dyes. The prepared materials also exhibited interesting sensing ability toward paramagnetic [Cu(II), Fe(III), Co(II)] and diamagnetic [Ag(I), $\mathrm{Hg}(\mathrm{II})]$ metal cations. Good photo-optical properties and processability of hybrid LPSQ-R-Py make them promising materials for possible applications in optoelectronics and metal cations sensing devices.

Supplementary Materials: The following are available online at http://www.mdpi.com/1996-1944/13/20/4491/s1, Synthetic procedures, Table S1: Composition of reaction mixtures during preparation of LPSQ/POSS-amide-Py; Figure S1: ${ }^{29} \mathrm{Si} \mathrm{NMR}\left(\mathrm{CDCl}_{3}\right)$ spectra of POSS-Cl and POSS-N 3 ; Figure S2: SEC analysis of LPSQ-N 3 ; Table S2: Molecular weight estimation based on SEC and NMR $\left({ }^{1} \mathrm{H},{ }^{29} \mathrm{Si}\right)$ analysis of LPSQ-Cl and LPSQ-N 3 ; Figure S3: ${ }^{29} \mathrm{Si}$ NMR $\left(\mathrm{CDCl}_{3}\right)$ spectra of LPSQ-Cl and LPSQ-N ${ }_{3}$; Figure S4: Thermogravimetric analysis of POSS-triazole-Py and POSS-amide-Py; Figure S5: DSC analysis of POSS-amide-Py; Table S3: IR band position assignments; Figure S6: AFM and WAXS analysis of silane-triazole-Py; Figure S7: Reflected light microscopy images of LPSQ-amide50-Py and POSS-amide-Py; Figure S8: Absorption spectra of LPSQ, POSS and silane-triazole-Py solutions in $\mathrm{CHCl}_{3}$ and THF; Figure S9: FL emission spectra of LPSQ and POSS-triazole-Py in $\mathrm{CHCl}_{3}$; Figure S10: Absorption spectra of LPSQ and POSS-amide-Py; Figure S11: Emission and excitation fluorescence spectra of silane-triazole-Py and POSS-amide-Py; Figure S12: Energy transfer from POSS-triazole-Py to Nile Red and Coumarin 6; Figure S13: Energy transfer from LPSQ-amide50-Py and POSS-amide-Py to Coumarin 6; Figure S14: Changes in FL emission intensity of LPSQ and POSS materials in the presence of metal cations; Figure S15: Changes in FL emission intensity of POSS-triazole-Py and POSS-amide-Py in the presence of cations.

Author Contributions: Conceptualization and writing: M.N. and A.K.; investigation, formal analysis and funding acquisition: M.N.; supervision and editing: A.K.; investigation and formal analysis (AFM and WAXS): T.M. All authors have read and agreed to the published version of the manuscript.

Funding: This research and the APC were funded by the Polish National Centre of Sciences (NCN), grant number 2016/21/N/ST5/03362.

Conflicts of Interest: The authors declare no conflict of interest.

\section{References}

1. Cho, S.; Hwang, N.; Lee, S.E.; Kim, Y.K.; Yoon, S.S. Highly efficient blue prganic light-emitting diodes based on diarylamine-substituted pyrene derivatives. J. Nanosci. Nanotechnol. 2019, 19, 1056-1060. [CrossRef] [PubMed]

2. Cai, G.; Xue, P.; Chen, Z.; Li, T.; Liu, K.; Ma, W.; Lian, J.; Zeng, P.; Wang, Y.; Han, R.P.S.; et al. High-performance mid-bandgap fused-pyrene electron acceptor. Chem. Mater. 2019, 31, 6484-6490. [CrossRef]

3. Feng, X.; Hu, J.-Y.; Redshaw, C.; Yamato, T. Functionalization of pyrene to prepare luminescent materials-typical examples of synthetic methodology. Chem. Eur. J. 2016, 22, 11898-11916. [CrossRef] [PubMed]

4. Winnik, F.M. Photophysics of preassociated pyrenes in aqueous polymer solutions and in other organized media. Chem. Rev. 1993, 93, 587-614. [CrossRef]

5. Figueira-Duarte, T.M.; Müllen, K. Pyrene-based materials for organic electronics. Chem. Rev. 2011, 111, 7260-7314. [CrossRef]

6. Armaroli, N.; Balzani, V. The future of energy supply: Challenges and opportunities. Angew. Chem. Int. Ed. 2007, 46, 52-62. [CrossRef]

7. Kundu, S.; Patra, A. Nanoscale strategies for light harvesting. Chem. Rev. 2017, 117, 712-757. [CrossRef] 
8. Sahoo, H. Förster resonance energy transfer-A spectroscopic nanoruler: Principle and applications. J. Photochem. Photobiol. C Photochem. Rev. 2011, 12, 20-30. [CrossRef]

9. Ferguson, J. Absorption and fluorescence spectra of crystalline pyrene. J. Chem. Phys. 1958, 28, 765. [CrossRef]

10. Vassiliev, S.; Bruce, D. Toward understanding molecular mechanisms of light harvesting and charge separation in photosystem II. Photosynth. Res. 2008, 97, 75-89. [CrossRef]

11. Wu, J.; Liu, W.; Ge, J.; Zhang, H.; Wang, P. New sensing mechanisms for design of fluorescent chemosensors emerging in recent years. Chem. Soc. Rev. 2011, 40, 3483-3495. [CrossRef] [PubMed]

12. Wu, D.; Sedgwick, A.C.; Gunnlaugsson, T.; Akkaya, E.U.; Yoon, J.; James, T. Fluorescent chemosensors: The past, present and future. Chem. Soc. Rev. 2017, 46, 7105-7123. [CrossRef] [PubMed]

13. Jeong, Y.; Yoon, J. Recent progress on fluorescent chemosensors for metal ions. Inorg. Chim. Acta 2012, 381, 2-14. [CrossRef]

14. Feng, J.; Tian, K.; Hu, D.; Wang, S.; Zeng, Y.; Li, Y.; Yang, Y. A triarylboron-based fluorescent thermometer: Sensitive over a wide temperature range. Angew. Chem. Int. Ed. 2011, 50, 8072-8076. [CrossRef]

15. Templer, R.H.; Castle, S.J.; Curran, A.R.; Rumbles, G.; Klug, D.R. Sensing isothermal changes in the lateral pressure in model membranes using di-pyrenyl phosphatidylcholine. Faraday Discuss. 1998, 111, 41-53. [CrossRef]

16. Faggi, E.; Serra-Vinardell, J.; Pandey, M.D.; Casas, J.; Fabriàs, G.; Luis, S.V.; Alfonso, I. Pseudopeptidic fluorescent on-off $\mathrm{pH}$ sensor based on pyrene excimer emission: Imaging of acidic cellular organelles. Sens. Actuators B Chem. 2016, 234, 633-640. [CrossRef]

17. Fujiwara, Y.; Amao, Y. Optical oxygen sensor based on controlling the excimer formation of pyrene-1-butylic acid chemisorption layer onto nano-porous anodic oxidized aluminium plate by myristic acid. Sens. Actuators B Chem. 2003, 89, 58-61. [CrossRef]

18. Kathiravan, A.; Gowri, A.; Khamrang, T.; Kumar, M.D.; Dhenadhayalan, N.; Lin, K.C.; Velusamy, M.; Jaccob, M. Pyrene-based chemosensor for picric acid-Fundamentals to smartphone device design. Anal. Chem. 2019, 91, 13244-13250. [CrossRef]

19. Zang, L.; Liang, C.; Wang, Y.; Bu, W.; Sun, H.; Jiang, S. A highly specific pyrene-based fluorescent probe for hypochlorite and its application in cell imaging. Sens. Actuators B Chem. 2015, 211, 164-169. [CrossRef]

20. Guo, Y.; Wang, L.; Zhuo, J.; Xu, B.; Li, X.; Zhang, J.; Zhang, Z.; Chi, H.; Dong, Y.; Lu, G. A pyrene-based dual chemosensor for colorimetric detection of $\mathrm{Cu}^{2+}$ and fluorescent detection of $\mathrm{Fe}^{3+}$. Tetrahedron Lett. 2017, 58, 3951-3956. [CrossRef]

21. Shen, T.; Jiang, N.; Zhang, X.; Lang, X.H.; Sun, J.Z.; Zhao, H. Probing Side Chain Dynamics of Branched Macromolecules by Pyrene Excimer Fluorescence. Polymers 2019, 11, 1366. [CrossRef] [PubMed]

22. Mitra, K.; Singh, S.; Hira, S.K.; Patel, V.K.; Singh, D.; Vishwakarma, S.; Singh, R.; Kumari, A.; Manna, P.P.; Ray, B. A Fluorescent Thermometer Based on a Pyrene-Labeled Thermoresponsive Polymer. ACS Biomater. Sci. Eng. 2016, 2, 1630-1640. [CrossRef]

23. Farhangi, S.; Duhamel, J. Probing side chain dynamics of branched macromolecules by pyrene excimer fluorescence. Macromolecules 2016, 49, 353-361. [CrossRef]

24. Ihara, E.; Okada, R.; Sogai, T.; Asano, T.; Kida, M.; Inoue, K.; Itoh, T.; Shimomoto, T.; Ishibashi, Y.; Asahi, T. Pd-mediated polymerization of diazoacetates with aromatic ester group: Synthesis and photophysical property of poly(1-pyrenylmethoxycarbonylmethylene). Polym. Chem. 2013, 5, 1020-1023. [CrossRef]

25. Pietsch, C.; Vollrath, A.; Hoogenboom, R.; Schubert, U.S. A Fluorescent Thermometer Based on a Pyrene-Labeled Thermoresponsive Polymer. Sensors 2010, 10, 7979-7990. [CrossRef]

26. Senthamizhan, A.; Celebioglu, A.; Bayir, S.; Gorur, M.; Doganci, E.; Yilmaz, F.; Uyar, T. Highly Fluorescent Pyrene-Functional Polystyrene Copolymer Nanofibers for Enhanced Sensing Performance of TNT. ACS Appl. Mater. Interfaces 2015, 7, 21038-21046. [CrossRef]

27. Lo, M.Y.; Zhen, C.; Lauters, M.I.; Jabbour, G.E.; Sellinger, A. Organic-Inorganic Hybrids Based on Pyrene Functionalized Octavinylsilsesquioxane Cores for Application in OLEDs. J. Am. Chem. Soc. 2007, 129, 5808-5809. [CrossRef]

28. Sellinger, A.; Tamaki, R.; Laine, R.M.; Ueno, K.; Tanabe, H.; Williams, E.; Jabbour, G.E. Heck coupling of haloaromatics with octavinylsilsesquioxane: Solution processable nanocomposites for application in electroluminescent devices. Chem. Commun. 2005, 3700-3702. [CrossRef]

29. Dong, Y.; Yang, Z.; Ren, Z.; Yan, S. Synthesis and the aggregation induced enhanced emission effect of pyrene based polysiloxanes. Polym. Chem. 2015, 6, 7827-7832. [CrossRef] 
30. Nowacka, M.; Kowalewska, A.; Plażuk, D.; Makowski, T. Hybrid polysilsesquioxanes for fluorescence resonance energy transfer. Dyes Pigment. 2019, 170, 107622. [CrossRef]

31. Kowalewska, A.; Nowacka, M. Synthesis of ladder silsesquioxanes by in situ polycondensation of cyclic tetravinylsiloxanetetraols. Silicon 2015, 7, 133-146. [CrossRef]

32. Kowalewska, A.; Nowacka, M.; Tracz, A.; Makowski, T. Supramolecular self-assembly of linear oligosilsesquioxanes on mica-AFM surface imaging and hydrophilicity studies. Soft Matter 2015, 11, 4818-4829. [CrossRef] [PubMed]

33. Krishnan, P.S.G.; He, C.; Shang, C.T. Synthesis, characterization, and curing kinetics of novel ladder-like polysilsesquioxanes containing side-chain maleimide groups. J. Polym. Sci. Polym. Chem. 2004, 42, 4036-4046. [CrossRef]

34. Dittmar, U.; Hendan, B.J.; Florke, U.; Marsmann, H.C. Funktionalisierte octa-(propylsilsesquioxane) $\left(3-\mathrm{XC}_{3} \mathrm{H}_{6}\right)_{8}\left(\mathrm{Si}_{8} \mathrm{O}_{12}\right)$ modellverbindungen für oberflächenmodifizierte kieselgele. J. Organomet. Chem. 1995, 489, 185-194. [CrossRef]

35. Slater, M.D.; Frechet, J.M.J.; Svec, F. In-column preparation of a brush-type chiral stationary phase using click chemistry and a silica monolith. J. Sep. Sci. 2009, 32, 21-28. [CrossRef]

36. Armarego, W.L.F.; Chai, C.L.L. Purification of Laboratory Chemicals, 5th ed.; Elsevier Science: Bodmin, UK, 2003.

37. Hypercube, Inc. HyperChem (TM); Version Professional 7.51; Hypercube, Inc.: Gainesville, FL, USA, 2019.

38. Chi, H.; Mya, K.Y.; Lin, T.; He, C.; Wang, F.; Chin, W.S. Thermally stable azobenzenedyes through hybridization with POSS. New J. Chem. 2013, 37, 735-742. [CrossRef]

39. Dong, F.; Ha, C.S. Multifunctional materials based on polysilsesquioxanes. Macromol. Res. 2012, 20, 335-343. [CrossRef]

40. Nowacka, M.; Fischer, C.; Kowalewska, A.; Hebda, M.; Hodor, K. Thermally induced phenomena leading to degradation of poly (silsesquioxane) materials. Eur. Polym. J. 2017, 86, 17-28. [CrossRef]

41. Ervithayasuporn, V.; Wang, X.; Kawakami, Y. Synthesis and characterization of highly pure azido-functionalized polyhedral oligomeric silsesquioxanes (POSS). Chem. Commun. 2009, 34, 5130-5132. [CrossRef]

42. Mittal, K.L. Polyimides and Other High Temperature Polymers: Synthesis, Characterization and Applications; CRC Press: Boca Raton, FL, USA, 2001; Volume 1.

43. Bräse, S.; Gil, C.; Knepper, K.; Zimmermann, V. Organic azides: An exploding diversity of a unique class of compounds. Angew. Chem. Int. Ed. 2005, 44, 5188-5240. [CrossRef]

44. L'abbe, G. Decomposition and addition reactions of organic azides. Chem. Rev. 1969, 69, 345-363. [CrossRef]

45. Trastoy, B.; Pérez-Ojeda, M.E.; Sastre, R.; Chiara, J.L. Octakis (3-azidopropyl) octasilsesquioxane: A versatile nanobuilding block for the efficient preparation of highly functionalized cube-octameric polyhedral oligosilsesquioxane frameworks through click assembly. Chem. Eur. J. 2010, 16, 3833-3841. [CrossRef] [PubMed]

46. Fernandes, D.S.; Maraldi, V.A.; Dias, F.N.L.; do Carmo, D.R. Reactivity of a silsesquioxane organofunctionalized with 4-Amino-5-Phenyl-4H-[1,2,4]-Triazole-3-thiol: Complementary characterization and an application to chronoamperometric detection of L-dopamine. Silicon 2019, 11, 1131-1142. [CrossRef]

47. Cordes, D.B.; Lickiss, P.D.; Rataboul, F. Recent developments in the chemistry of cubic polyhedral oligosilsesquioxanes. Chem. Rev. 2010, 110, 2081-2173. [CrossRef] [PubMed]

48. Wu, W.H.; Thomas, P.; Hume, P.; Jin, J. Effective conversion of amide to carboxylic acid on Polymers of Intrinsic Microporosity (PIM-1) with nitrous acid. Membranes 2018, 8, 20. [CrossRef]

49. Ervithayasuporn, V.; Chimjarn, S. Synthesis and isolation of methacrylate and acrylate-functionalized polyhedral oligomeric silsesquioxanes $\left(\mathrm{T}_{8}, \mathrm{~T}_{10}\right.$, and $\left.\mathrm{T}_{12}\right)$ and characterization of the relationship between their chemical structures and physical properties. Inorg. Chem. 2013, 52, 13108-13112. [CrossRef]

50. Kowalewska, A.; Nowacka, M.; Włodarska, M.; Zgardzińska, B.; Zaleski, R.; Oszajca, M.; Krajenta, J.; Kaźmierski, S. Solid-state dynamics and single-crystal to single-crystal structural transformations in octakis (3-chloropropyl) octasilsesquioxane and octavinyloctasilsesquioxane. Phys. Chem. Chem. Phys. 2017, 19, 27516-27529. [CrossRef]

51. Chimjarn, S.; Kunthom, R.; Chancharone, P.; Sodkhomkhum, R.; Sangtrirutnugul, P.; Ervithayasuporn, V. Synthesis of aromatic functionalized cage-rearranged silsesquioxanes (T8, T10, and T12) via nucleophilic substitution reactions. Dalton Trans. 2015, 44, 916-919. [CrossRef] 
52. Kopesky, E.T.; Boyes, S.G.; Treat, N.; Cohen, R.E.; McKinley, G.H. Thermorheological properties near the glass transition of oligomeric poly (methyl methacrylate) blended with acrylic polyhedral oligomeric silsesquioxane nanocages. Rheol. Acta 2006, 45, 971-981. [CrossRef]

53. Cheng, C.-C.; Chang, F.-C.; Dai, S.A.; Lin, Y.-L.; Lee, D.-J. Bio-complementary supramolecular polymers with effective self-healing functionality. RSC Adv. 2015, 5, 90466-90472. [CrossRef]

54. Kowalewska, A.; Fortuniak, W.; Handke, B. New hybrid silsesquioxane materials with sterically hindered carbosilane side groups. J. Organomet. Chem. 2009, 694, 1345-1353. [CrossRef]

55. Nowacka, M.; Kowalewska, A.; Makowski, T. Structural studies on ladder phenylsilsesquioxane oligomers formed by polycondensation of cyclotetrasiloxanetetraols. Polymer 2016, 87, 81-89. [CrossRef]

56. Unno, M.; Akiko, S.; Keisuke, T.; Hideyuki, M. Synthesis of Ladder and Cage Silsesquioxanes from 1,2,3,4-Tetrahydroxycyclotetrasiloxane. Bull. Chem. Soc. Jpn. 2000, 73, 215-220.

57. Ge, Y.; Wen, Y.; Liu, H.; Lu, T.; Yu, Y.; Zhang, X.; Li, B.; Zhang, S.-T.; Li, W.; Yang, B. A key stacking factor for the effective formation of pyrene excimer in crystals: Degree of $\pi-\pi$ overlap. J. Mater. Chem. C 2020, 8 , 11830-11838. [CrossRef]

58. Makal, A.; Krzeszczakowska, J.; Gajda, R. Pressure-dependent structural and luminescence properties of 1-(Pyren-1-yl) but-2-yn-1-one. Molecules 2019, 24, 1107. [CrossRef]

59. Ishida, Y.; Tada, Y.; Hirai, T.; Goseki, R.; Kakimoto, M.; Yoshida, H.; Hayakawa, T. Directed self-assembly of cage silsesquioxane containing block copolymers via graphoepitaxy techniques. J. Photopolym. Sci. Technol. 2010, 23, 155-159. [CrossRef]

60. Stark, R.W.; Heckl, W.H. Fourier transformed atomic force microscopy: Tapping mode atomic force microscopy beyond the Hookian approximation. Surf. Sci. 2000, 457, 219-228. [CrossRef]

61. Bowen, W.R.; Doneva, T.A. Artefacts in AFM studies of membranes: Correcting pore images using fast fourier transform filtering. J. Membr. Sci. 2000, 171, 141-147. [CrossRef]

62. Silva, N.J.; Machado, F.B.C.; Lischka, H.; Aquino, A.J.A. $\pi-\pi$ stacking between polyaromatic hydrocarbon sheets beyond dispersion interactions. Phys. Chem. Chem. Phys. 2016, 18, 22300-22310. [CrossRef]

63. Duhamel, J. New insights in the study of pyrene excimer fluorescence to characterize macromolecules and their supramolecular assemblies in solution. Langmuir 2012, 28, 6527-6538. [CrossRef]

64. Birks, J.B. Excimers. Rep. Prog. Phys. 1975, 38, 903-974. [CrossRef]

65. Fujii, A.; Sekiguchi, Y.; Matsumura, H.; Inoue, T.; Chung, W.S.; Hirota, S.; Matsuo, T. Excimer emission properties on pyrene-labeled protein surface: Correlation between emission spectra, ring stacking modes, and flexibilities of pyrene probes. Bioconjug. Chem. 2015, 26, 537-548. [CrossRef] [PubMed]

66. Niko, Y.; Hiroshige, Y.; Kawauchi, S.; Konishi, G. Additional insights into luminescence process of polycyclic aromatic hydrocarbons with carbonyl groups: Photophysical properties of secondary N-Alkyl and tertiary N, N-Dialkyl carboxamides of naphthalene, anthracene, and pyrene. J. Org. Chem. 2012, 77, 3986-3996. [CrossRef] [PubMed]

67. Wrona-Piotrowicz, A.; Zakrzewski, J.; Métivier, R.; Brosseau, A.; Makal, A.; Woźniak, K. Efficient synthesis of pyrene-1-carbothioamides and carboxamides. Tunable solid-state fluorescence of pyrene-1-carboxamides. RSC Adv. 2014, 4, 56003-56012. [CrossRef]

68. Lekha, P.K.; Ghosh, T.; Prasad, E. Utilizing dendritic scaffold for feasible formation of naphthalene excimer. J. Chem. Sci. 2011, 123, 919-926. [CrossRef]

69. Grigalevicius, S.; Forster, M.; Ellinger, S.; Landfester, K.; Scherf, U. Excitation energy transfer from semi-conducting polymer nanoparticles to surface-bound fluorescent dyes. Macromol. Rapid Commun. 2006, 27, 200-202. [CrossRef]

70. Bhattacharyya, S.; Jana, B.; Patra, A. Multichromophoric organic molecules encapsulated in polymer nanoparticles for artificial light harvesting. ChemPhysChem 2015, 16, 796-804. [CrossRef]

71. Chai, J.; Wu, Y.; Yang, B.; Liu, B. The photochromism, light harvesting and self-assembly activity of a multi-function schiff-base compound based on the AIE effect. J. Mater. Chem. C 2018, 6, 4057-4064. [CrossRef]

72. Dietz, E.M. Chlorophyll and hemoglobin-Two natural pyrrole pigments. J. Chem. Educ. 1935, 12, 208. [CrossRef]

73. Sadiq, S.; Ghazala, Z.; Chowdhury, A.; Busselberg, D. Metal toxicity at the synapse: Presynaptic, postsynaptic, and long-term effects. J. Toxicol. 2011, 2012, 132671. [CrossRef]

74. Thirupathi, P.; Lee, K.H. A ratiometric fluorescent detection of $\mathrm{Zn}$ (II) in aqueous solutions using pyrene-appended histidine. Bioorg. Med. Chem. Lett. 2013, 23, 6811-6815. [CrossRef] [PubMed] 
75. Raj, T.; Saluja, P.; Singh, N. A new class of pyrene based multifunctional chemosensors for differential sensing of metals in different media: Selective recognition of $\mathrm{Zn}^{2+}$ in organic and $\mathrm{Fe}^{3+}$ in aqueous medium. Sens. Actuators B 2015, 206, 98-106. [CrossRef]

76. Chung, P.K.; Liu, S.R.; Wang, H.F.; Wu, S.P.J. A Pyrene-based highly selective turn-on fluorescent chemosensor for iron (III) ions and its application in living cell imaging. J. Fluoresc. 2013, 23, 1139-111145. [CrossRef] [PubMed]

77. Manandhar, E.; Wallace, K.J. Host-guest chemistry of pyrene-based molecular receptors. Inorg. Chim. Acta 2012, 381, 15-43. [CrossRef]

78. Formica, M.; Fusi, V.; Giorgi, L.; Micheloni, M. New fluorescent chemosensors for metal ions in solution. Coord. Chem. Rev. 2012, 256, 170-192. [CrossRef]

79. Parker, D.; Williams, J.A.G. Luminescence behaviour of cadmium, lead, zinc, copper, nickel and lanthanide complexes of octadentate macrocyclic ligands bearing naphthyl chromophores. J. Chem. Soc. Perkin Trans. 1995, 2, 1305-1314. [CrossRef]

80. Bergonzia, R.; Fabbrizzi, L.; Licchellia, M.; Manganoa, C. Molecular switches of fluorescence operating through metal centred redox couples. Coord. Chem. Rev. 1998, 170, 31-46. [CrossRef]

81. Fages, F.; Bodenant, B.; Weil, T. Fluorescent, siderophore-based chelators. design and synthesis of a trispyrenyl trishydroxamate ligand, an intramolecular excimer-forming sensing molecule which responds to iron (III) and gallium (III) metal cations. J. Org. Chem. 1996, 61, 3956-3961. [CrossRef]

82. Maity, D.; Raj, A.; Karthigeyan, D.; Kundu, T.K.; Govindaraju, T. Reaction-based probes for Co (II) and Cu (I) with dual output modes: Fluorescence live cell imaging. RSC Adv. 2013, 3, 16788-16794. [CrossRef]

83. Reimann, C.; Koller, F.; Kashulina, G.; Englmaier, H.P. Influence of extreme pollution on the inorganic chemical composition of some plants. Environ. Pollut. 2001, 115, 239-252. [CrossRef]

84. Zhu, M.; Wang, W.; Liu, J.; Na, R.; Li, Z.; Wang, Y. A novel pyrene-based fluorescent probe for the rapid and efficient detection of $\mathrm{Co}^{2+}$ in HeLa cells and natural water samples. J. Mol. Liq. 2020, 303, 112680. [CrossRef]

85. Mohandoss, S.; Stalin, T. A new fluorescent PET sensor probe for $\mathrm{Co}^{2+}$ ion detection: Computational, logic device and living cell imaging applications. RSC Adv. 2017, 7, 16581-16593. [CrossRef]

86. Shiraishi, Y.; Ishizumi, K.; Nishimura, G.; Hirai, T. Effects of metal cation coordination on fluorescence properties of a diethylenetriamine bearing two end pyrene fragments. J. Phys. Chem. B 2007, 111, 8812-8822. [CrossRef] [PubMed]

Publisher's Note: MDPI stays neutral with regard to jurisdictional claims in published maps and institutional affiliations.

(C) 2020 by the authors. Licensee MDPI, Basel, Switzerland. This article is an open access article distributed under the terms and conditions of the Creative Commons Attribution (CC BY) license (http://creativecommons.org/licenses/by/4.0/). 